NBER WORKING PAPER SERIES

\title{
HOW DO HOSPITALS RESPOND TO MARKET ENTRY? EVIDENCE FROM A DEREGULATED MARKET FOR CARDIAC REVASCULARIZATION
}

\author{
Suhui Li \\ Avi Dor \\ Working Paper 18926 \\ http://www.nber.org/papers/w18926 \\ NATIONAL BUREAU OF ECONOMIC RESEARCH \\ 1050 Massachusetts Avenue \\ Cambridge, MA 02138 \\ March 2013
}

We thank Shin-Yi Chou, Mary E. Deily, James A. Dearden, Yang Wang, and seminar participants at the Lehigh Economics Department, George Washington University, and the Federal Trade Commission Bureau of Economics for helpful comments. Much of the data used in this analysis was from the Pennsylvania Health Care Cost Containment Council (PHC4). The PHC4 is an independent state agency responsible for addressing the problem of escalating health costs, ensuring the quality of health care, and increasing access to health care for all citizens regardless of ability to pay. PHC4 has provided data to this entity in an effort to further PHC4's mission of educating the public and containing health care costs in Pennsylvania. PHC4, its agents, and staff, have made no representation, guarantee, or warranty, express or implied, that the data - financial, patient, payer, and physician specific information - provided to this entity, are error-free, or that the use of the data will avoid differences of opinion or interpretation. This analysis was not prepared by PHC4. This analysis was done by Suhui Li and Avi Dor. PHC4, and its agents and staff bear no responsibility or liability for the results of the analysis, which are solely the opinion of the authors. Avi Dor acknowledges funding support from NIH. The views expressed herein are those of the authors and do not necessarily reflect the views of the National Bureau of Economic Research.

NBER working papers are circulated for discussion and comment purposes. They have not been peerreviewed or been subject to the review by the NBER Board of Directors that accompanies official NBER publications.

(C) 2013 by Suhui Li and Avi Dor. All rights reserved. Short sections of text, not to exceed two paragraphs, may be quoted without explicit permission provided that full credit, including $(\mathrm{C}$ notice, is given to the source. 
How Do Hospitals Respond to Market Entry? Evidence from A Deregulated Market for Cardiac Revascularization

Suhui Li and Avi Dor

NBER Working Paper No. 18926

March 2013

JEL No. I1,L4,L5

\begin{abstract}
Regulatory entry barriers to hospital service markets, namely Certificate of Need (CON) regulations, are enforced in many states; although no longer federally mandated, policy makers in other states are considering reinstating CON policies in tandem with service expansions mandated under the Affordable Care Act. While numerous studies have examined the impacts of CON on hospital volumes, demand responses to actual hospital entry into local hospital markets are not well understood. In this paper, we empirically examine the demand-augmenting, demand-redistribution, and risk-allocation effects of hospital entry by studying the cardiac revascularization markets in Pennsylvania, a state in which dynamic market entry occurred after repeal of CON in 1996. Our findings with respect to demand-augmentation are mixed: we find robust evidence that high entrant market share mitigated the declining incidence of coronary artery bypass graft $(\mathrm{CABG})$, but it had no significant effect on the rising trend in percutaneous coronary intervention (PCI) procedures, among patients with coronary artery disease. Consequently, incumbent hospitals experienced a decrease in the likelihood of PCI due to entry, thereby indicating a shift in demand away from incumbents to entrants, namely business-stealing. Results of our analyses further indicate that entry by new cardiac surgery centers tended to sort high-severity patients into the more invasive CABG procedure and low-severity patients into the less invasive PCI procedures. Thus, from a welfare perspective our results are mixed: on the one hand, free-entry may lead to improved access rather than business stealing for $\mathrm{CABG}$ procedures; on the other hand, the empirical evidence is in favor of business-stealing for PCI procedures. Moreover, free-entry improves the match between underlying medical risk and treatment intensity. These findings underscore the importance of considering market-level strategic responses by hospitals when regulatory barriers to entry are rescinded.
\end{abstract}

Suhui Li

Assistant Professor

Department of Health Policy

George Washington University

2021 K Street, Suite 800

Washington, DC 20037

suhuili@gwu.edu

Avi Dor

Professor

George Washington University

2021 K street NW, Suite 800

Washington, DC 20037

and NBER

avidor@gwu.edu 


\section{Introduction}

Regulatory entry barriers, while considered detrimental to market efficiency in most industries, are widely used in health care. In particular, many states enforce Certificate of Need (CON) regulation, whereby hospitals are required to obtain approval from a designated state agency before installing additional capacity or prior to offering certain high cost services. Although a Federal law which required all states to maintain CON regulation for cardiac care expired in 1986, states were slow to deregulate the market. As recently as 2011, cardiac CON continued to be in place in 26 states (AHPA, 2011). Moreover, new forms of quality monitoring recently introduced under the Affordable Care Act (ACA) have rekindled interest in state-based regulation, with several states currently reinstituting CON programs (Sharamitaro and Drew, 2011) ${ }^{1}$.

Proponents of CON argue that regulation is needed to curtail overuse of technologyintensive services, a phenomenon previously referred to as the medical "arms race" (Luft, 1986). Furthermore, proponents theorized that entry barriers promote higher quality and help to rein in costs by maintaining higher-volume clinical programs with established expertise. Opponents make the more traditional argument that entry barriers protect inefficient producers by shielding them from competition. In a joint report the Federal Trade Commission and the Department of Justice (2008) noted that "existing competitors have exploited the CON process to thwart or delay new competition to protect their own supra-competitive revenues."

Previous research attempted to shed light on the policy debate by evaluating impacts in states that kept or dropped CON regulation. Focusing on health outcomes associated with major cardiac procedures, notably mortality, Ho et al. (2009) and Popescu, Vaughan-Sarrazin, and Rosenthal (2006), find small or no difference between the groups of states. Another study by Ho

\footnotetext{
${ }^{1}$ Quality monitoring aspects of the ACA include reduced federal payments to hospitals for excess mortality for a number of medical conditions, notably heart attacks, and a requirement that hospitals meet community needs assessment criteria to maintain their tax-exempt status.

2 "Competition in Health Care and Certificates of Need - Joint Statement of the Antitrust Division of the U.S. Department of Justice and the Federal Trade Commission Before the Illinois Task Force on Health Planning Reform.” http://www.justice.gov/atr/public/comments/237351.htm\#N_1_
} 
(2006) uses simulation methods to identify difference in treatment costs between CON and nonCON states, finding that CON was associated with relatively small reductions in costs. Turning to volume effects, Popescu et al. find significantly lower use rates in states with CON, while Ho (2006) found no significant difference in the statewide procedure volume between states with and without CON. Using a difference in difference approach, Ho et al. (2009) found that the number of hospitals performing cardiac revascularization rose in states that repealed $\mathrm{CON}$, coupled by offsetting decreases in average hospital volume in these states.

While studies focusing on the impact of discrete policy events are important, they do not necessarily capture heterogeneity within states that are targeted by the intervention. In this study we focus on understanding volume effects more deeply, taking within-state heterogeneity into account. In particular, we seek to empirically explain responses to actual hospital entry into local cardiac markets as they occurred in the aftermath of $\mathrm{CON}$ repeal, differentiating between incumbent hospitals and all other market participants combined. To implement this approach, we focus on Pennsylvania, a state in which dynamic market entry occurred after repeal of CON in 1996, allowing us to observe the distribution of low and high entry rates both longitudinally and across small market areas. For similar reasons Pennsylvania was also used as the case study by Cutler et al. (2010) in their empirical study of CON regulation affecting cardiac surgeons. ${ }^{3}$ Additionally, we adopt an interrupted time series design to account for discontinuity in trends before and after repeal of CON (Finkelstein, 2007). Following much of the literature cited in this paper we focus on two major cardiac procedures, jointly referred to as cardiac "revascularization", namely coronary artery bypass graft $(\mathrm{CABG})^{4}$ and percutaneous coronary intervention (PCI) ${ }^{5}$,

\footnotetext{
${ }^{3}$ Cutler et al. point out that facing with a highly inelastic supply of cardiac surgeons, entrant hospitals are more likely to contract with higher-quality cardiac surgeons, which in turn leads to a welfare-enhancing redistribution of patients from lower-quality to higher-quality surgeons. Empirically, they show that topperforming cardiac surgeons received increased $\mathrm{CABG}$ volume following the entry of new CABG hospitals. ${ }^{4} \mathrm{CABG}$ is a surgical procedure which involves surgically isolating a section of a vein or artery and grafting it to create a bypass of blockage in the coronary artery. It was developed in the late 1960s and entered mainstream use in the United States during the 1970s, largely performed on patients whose indications represent a significant risk of heart attack.
} 
which are relatively common and well identifiable in administered databases. Specifically, we explore how entrants' market shares affect the likelihood of undergoing the more intensive CABG and the relatively less intensive PCI for patients with coronary artery disease (CAD), as well as the likelihood of encountering these treatments at incumbent hospitals before and after deregulation.

By focusing on shifts in patient volume, we are able to further hone in on strategic responses related to the distribution of patients by levels of risk and illness severity. While previous research has explored this issue of risk allocation in the context of hospital competition in general (Capps, Dranove, Satterthwaite, 2003; Kessler and Geppert, 2005) ${ }^{6}$, the allocation of low risk versus high risk patients has not been previously studied in relation to either CON regulation or market entry specifically. This latter analysis, which we implement, carries certain welfare implications as well: from the patient's perspective, does resorting after market entry lead to appropriate intensity of care? From the hospital perspective, do entrants exhibit "business stealing" behavior (e.g., Mankiw and Whinston, 1986; Bresnahan and Reiss, 1990, 1991), such that incumbents are left with a greater proportion of high-risk patients in the post-deregulation period?

Thus, our analysis complements and extends previous studies by exploring the interaction of CON deregulation and the degree of market entry. Moreover, unlike previous studies of CON, we focus on changes in patient volume at the level of local markets, rather than hospital averages. Furthermore, we analyze the reallocation of patients based on severity, among incumbents and

\footnotetext{
${ }^{5}$ The PCI procedure involves only a small incision through which a balloon-tipped catheter is threaded and inflated within the coronary artery to improve the blood supply. PCI is less invasive compared to CABG, and more often performed on patients with relatively mild CAD. PCI was formerly labeled PTCA, and more commonly referred to as angioplasty.

${ }^{6}$ Capps et al. note that low risk and high risk patients differ in their valuations of health care, leading them to differ in their willingness to switch to competitors; Kessler and Geppert show that clinically appropriate sorting of low risk and high risk patients into low intensity and high intensity hospital treatments is enhanced when markets are locally competitive.
} 
other hospitals, and between high-intensity $(\mathrm{CABG})$ and low intensity procedures $(\mathrm{PCI})$, thereby shedding light on an issue not previously considered.

The rest of the paper proceeds as follows. Section II lays out the main hypotheses to be tested, and provides a related review of the literature. Section III discusses the market for cardiac care in Pennsylvania, and provides background behind CON laws in that state. Section IV describes the data and presents summary statistics. Section V describes the empirical models for identifying the effects of entry on patient allocation, while controlling for prior trends. Section VI presents the empirical results, showing that they are robust to alternative specifications. Section VII concludes.

\section{Main Issues and Related Literature}

In the previous section we noted prior literature on the effects of $\mathrm{CON}$ which relied on between-state comparisons to identify changes in volume and aggregate demand. A separate strain of the literature has focused on strategic responses to market entry by new health care providers, independently of CON. Yet few studies have explored market reactions to free entry specifically in the aftermath of CON deregulation. In this study, we aim to fill the gap, thereby combining and extending both research themes. Below we survey the literature on entry in relation to the main hypotheses to be tested in our empirical analysis. We label these hypotheses as the demand augmenting effect, the demand redistribution effect, and define two variants of patients risk allocation effects, first by type of hospital, and second by treatment intensity:

1. Demand-augmenting Effect - Previous studies have shown that market entry by hospitals and other health care centers can lead to higher volume. For instance, using the structure-conduct-performance (SCP) framework developed by Bresnahan and Reiss ${ }^{7}$, Abraham

\footnotetext{
${ }^{7}$ Bresnahan and Reiss $(1990,1991)$ model firms' entry decision as the equilibrium outcome of a discrete game played between potential entrants. The general entry condition suggests that as intensified competition shrinks profit margin, entrants need a larger population to generate enough revenue to cover fixed entry costs. Thus examining the relationship between the number of firms and the market size allows the authors to determine whether additional firms generate additional revenue or just steal business from incumbent rival firms.
} 
et al. (2007) presented evidence that hospital entry substantially expands market demand and tightens competition. Similarly, Mitchell (2007) found substantial increases in utilization rates following the entry of specialty hospitals, even after controlling for area specific effects. While it is difficult to empirically distinguish between volume increases that occur due to entrants' response to unmet needs (pent up demand) and volume increases representing creation of new demand by entrants (inducement), anecdotal evidence suggests that inducement may have been the culprit. For instance, Burns et al. (2009) found that the rapid growth in Arizona's cardiac surgery volume, which was accompanied by entry, exceeded population growth and aging trends. In this paper we do not attempt to enter the debate over inducement. Rather, we are initially interested in describing trends in the aggregate demand for CABG and PCI, and their association with market entry, in order to establish the potential for strategic behavior as described below ${ }^{8}$. Note that while the above studies provide evidence on the aggregate demand response to entry, they do not explain how entry affects treatment choices and patients' redistribution.

2. Demand-redistribution Effect (business stealing) — Entry that shifts demand from incumbent firms to entrants is generally referred to as "business-stealing" (Mankiw and Whinston, 1986; Bresnahan and Reiss, 1990, 1991). In our context, entrants (namely new cardiac surgery centers) may attract patients from incumbent hospitals rather than augment existing demand. Prior studies examining volume shifts in response to hospital entry are sparse. However, Huckman (2006) examines shifts in the volume of cardiac care from acquired hospitals to acquiring hospitals, using small area market shares and concludes that acquirers benefited from business stealing. Dafny (2005) has shown that incumbent hospitals strategically increase their own volume in order to deter potential entry into high-end cardiac treatments, suggesting that the

\footnotetext{
${ }^{8}$ Mankiw and Whinston (1986) note that when entry causes a sufficient rise in the aggregate demand so that incumbent firms' demand is not affected (no business-stealing effect), free entry will create net social benefits through newly created demand. In health care markets, however, asymmetric information between providers and patients, may induce demand beyond optimal treatment levels, so that the additional demand may not be welfare enhancing.
} 
perceived threat of business stealing is pervasive in these markets ${ }^{9}$. Given that incumbent market share is necessarily reduced when new firms enter the market ${ }^{10}$, in this study we are able to infer business stealing effects from changes in the likelihood of receiving cardiac treatment at incumbent hospitals associated with entry into an incumbent's local market area. We base our analysis on patient level regressions, which allows for detailed risk adjustment using the patient's clinical characteristics while incorporating market-level variables, notably the share of entrants in treatment volume within the local market area. Predicted entrant market share is constructed using a method used by Kessler and McClellan (2000) (see Appendix).

3. Risk-allocation Effect (Patient sorting) - refers to the allocation of high risk patients and low risk patients into incumbent hospitals versus entrant hospitals. To the extent business stealing is found, its effects may be more harmful from the perspective of incumbents if for a given medical condition, relatively healthy patients ("low-risk") are drawn away by entrant hospitals while sicker patients ("high-risk") remain with incumbents. Rephrasing, we ask whether entrants exhibit business stealing behavior such that incumbents are left with a greater proportion of highrisk patients following deregulation ${ }^{11}$.

Previous studies found evidence that specialty cardiac hospitals tend to serve relatively healthier patients than general hospitals (Barro et al., 2006; Cram et al., 2005) and tend to enter markets in which cardiac patients are healthier to begin with (Barro et al., 2006). However, given their interest in specialty hospital reimbursement issues, these studies took a narrow view of

\footnotetext{
${ }^{9}$ Ellison and Ellison (2011) find similar results in the case of the pharmaceutical industry, where investment in research and development in established product lines acts as a deterrent for potential entry by new drug developers.

${ }^{10}$ As an illustrative example, let $\Delta D=\Delta D_{1}+\Delta D_{2}$, where $\Delta D, \Delta D_{1}$, and $\Delta D_{2}$ denote the change in total demand, change in incumbent demand, and change in entrant demand, respectively. Assume that the baseline market volume was 100, and that following entry, $\Delta D=10, \Delta D_{1}=0$, and $\Delta D_{2}=10$. In this case, even though the incumbent share declines from 1 to $0.91(=100 / 110)$, there is no business stealing, because the entrant obtains its market share through creating new demand.

${ }^{11}$ Note that under the Medicare Prospective Payment System (PPS) hospitals receive a fixed payment for a given diagnosis with minimal compensation for outlier costs; for the most part, private insurers also use PPS or similar fixed-price reimbursement methods that do not provide for full risk adjustment (Capps and Dranove, 2004). Thus, high risk patients are also less profitable for the hospital.
} 
market entry and did not consider broader entry due to openings of new cardiac centers within established general hospitals. In addition, these studies did not model the interaction between entrant share and patient "riskiness", which would allow one to explore the degree to which business stealing by entrants correlates with risk. In this paper, we seek to address both of these issues by focusing on Pennsylvania, where all cardiac surgery centers were affiliated with general hospitals during our sample period, and by incorporating the interaction patient risk and entrant share in patient-level analyses of the likelihood of receiving cardiac surgeries at incumbent hospitals. The manner in which we interact the low-risk and high-risk patient designations with entry share categories is analogous to Kessler and Geppert (2005) who examined the effects of hospital competition and patient risk on hospital expenditures for Medicare patients with heart attacks. Their results showed that competition led to increased variation in risk-based inpatient expenditures, suggesting that contrary to standard oligopoly theory, competition leads to greater product differentiation in the special case of hospital care ${ }^{12}$.

More generally, we are interested in knowing the extent to which observed changes in demand are actually related to the repeal of $\mathrm{CON}$, rather than a reflection in long-term trends that may be unrelated to policy changes. Nationally, the rate for CABG (the high intensity procedure) steadily declined during the past decade while the rate for PCI (the low intensity procedure) has remained stable (Epstein et al., 2011). Previous studies noted the introduction and diffusion of stent coronary angioplasty (one type of PCI) in the mid-1990s contributed to the declining rate of CABG by shifting many patients from CABG to PCI (Cutler and Huckman 2003; Epstein et al. 2011). However, recent clinical trials indicate that $C A B G$ remains the treatment of choice for

\footnotetext{
${ }^{12}$ Although Kessler and Geppert do not discuss this, Hotelling's (1929) duopoly model of spatial location serves as the basis for this hypothesis. The standard Hotelling model predicts that competition leads the two firms to move towards the center in a linear market, a result that is referred to as the "principle of minimum differentiation". Accordingly, market entry would not change the level of specialty or risk differentiation by hospitals. However, applying the Hotelling model to the unique circumstances of the hospital industry, Calem and Rizzo (1995) and Brekke et al. (2006) show that when prices are regulated, there is an incentive for hospitals to move further apart on the service mix space in order to dampen the quality competition.
} 
patients with severe coronary arterial disease as it achieves better health outcomes than PCI

(Serruys et al., 2009). Given the longitudinal nature of our data from Pennsylvania, one concern is that our estimates of demand augmentation may reflect a general time trend in cardiac treatment rates that began prior to the repeal of $\mathrm{CON}$, which may confound our estimates of the trend due to $\mathrm{CON}$ and related effects of post-deregulation entry. To address this concern, we adopt a differences-in-trend design akin to that found in Finkelstein's (2007) study on the effects of Medicare's introduction.

\section{Pennsylvania's Cardiac Care Market and CON Regulation}

With the repeal of CON laws in several states following a change in Federal law dating back to 1986, hospitals have faced opposing incentives for entering newly opened markets for cardiac services. On the one hand, cardiovascular disease is a highly prevalent condition in the population and a potentially large source of revenues, currently accounting for about a third of inpatient revenues nationally. On the other hand, entry costs into this market may be prohibitively high, with an initial investment in a new revascularization centers reportedly ranging from $\$ 12$ to \$14 million (Robinson et al. 2001; Huckman 2006). Therefore, high entry costs may dampen the effects of deregulation in this market. Although a number of studies examined aggregate changes in volume due to the repeal of CON regulations ${ }^{13}$, the issue of strategic responses by hospitals to entry that ensued deregulation has not been fully explored. Pennsylvania, a state in which dynamic entry occurred following its repeal of CON, provides a useful test case (Longwell, 2011). Pennsylvania repealed its comprehensive state CON program in December 1996, thereby allowing hospitals to provide new services, including cardiac surgeries, without having to obtain permission from the state's regulators. Recently however, public interest in the state's CON

\footnotetext{
${ }^{13}$ For instance, Ho et al. (2009) found that while the number of hospitals performing cardiac revascularization rose in states that repealed CON between 1989 and 2002, overall volume in these states remained essentially unchanged due to offsetting decreases in average hospital volume.
} 
program has been rekindled, and legislative attempts to reinstate the program are currently underway. $^{14}$

Figure 1 illustrates the striking increase in the number of cardiac surgery centers after the 1996 repeal of CON relative to the pre-policy trend. Five centers, all of whom were located in general hospitals, entered the market immediately after the repeal, consequently increasing the total number of providers from 43 to 48 . By 2004, there were a total of 28 post-CON new entrants, accounting for $41 \%$ of all hospitals providing cardiac revascularization in Pennsylvania. ${ }^{15}$ The majority of entry occurred in urban or suburban areas. All cardiac surgery centers in Pennsylvania were affiliated with general acute hospitals rather than cardiac specialty hospitals.

Figure 2 shows the type of procedures provided by new entrants since the 1996 repeal of CON. A hospital is considered to be a participant in the market for CABG in a particular year if it performed at least 5 CABGs in that year (Magid et al, 2007, Nallamothu et al, 2007). ${ }^{16}$ The same threshold is used to identify PCI hospitals. Although PCIs are less invasive than CABGs, and are performed in catheterization laboratories instead of operating rooms, hospitals performing PCIs are required to have on-site surgical backup in case an emergency CABG is needed following a failed PCI. For this reason, all participating hospitals in Pennsylvania had provided both types of procedures before the 2000s. However, as PCI became nationally more diffused in the mid-1990s, some of the new entrants began specializing in PCI only. As shown in Figure 2, only one of the six new entrants during 2003 and 2004 was providing both procedures; the other five were providing only PCI procedures. This trend suggests that the cardiac revascularization markets in Pennsylvania may be evolving toward a greater degree of treatment specialization following the

\footnotetext{
${ }^{14} \mathrm{See}$ http://www.legis.state.pa.us/cfdocs/Legis/CSM/showMemoPublic.cfm?chamber=S\&SPick=20130\&cospon $\underline{\mathrm{Id}=10038}$, and $\mathrm{http}: / /$ wesa.fm/2012/05/08/proposed-legislation-calls-certificate-need. Both accessed on January 14, 2013.

${ }^{15}$ During the sample period, St. Francis Medical Center and Medical College of Pennsylvania closed on 2001 and 2004. UPMC Shadyside merged with UPMC Presbyterian in 2003. As a result, the total number of cardiac surgery centers was 68 by 2004 .

${ }^{16}$ In our main analysis, entrants are defined as hospitals that started performing CABG or PCI procedures as of 1997, (more than 5 CABG or PCI cases in a given year) with no cases in previous years.
} 
entry of new programs.

\section{Data and Sample}

This study uses longitudinal inpatient records of all CAD patients who reside in Pennsylvania from 1995 through 2004 to investigate the effects of free entry in cardiac revascularization markets. The data is collected by the Pennsylvania Health Care Cost Containment Council (PHC4), and provides a wide range of patient clinical and utilization information including diagnosis/procedure codes, admission type and source, discharge status, and charges. It also includes patient demographic information such as age, gender, race, insurance type, and zip code of residence. A unique patient identifier allows us to track each individual's inhospital records over time.

The PHC4 also records patient's illness severity using the MediQual score, which is calculated based on patient characteristics and key clinical variables abstracted from admission medical records including vital signs, other physical findings, historical factors, and radiographic and laboratory findings (Lezzoni and Moskowtiz, 1988). This severity measure ranges from 0 to 4 , with 4 being the most severe. The MediQual score captures not only acute symptoms, but also long-term conditions that may affect the patient's baseline health status.

The second source of data for this study is the American Hospital Association (AHA) Annual Survey of Hospitals. Each admission record in the PHC4 data is associated with a unique facility identifier, which enables us to link it to comprehensive facility characteristics in the AHA data, including location (longitude and latitude), bed capacity, teaching status, ownership, and system member status.

Our study sample includes Pennsylvania residents who were admitted to any hospital in the state with a new diagnosis of $\mathrm{CAD}^{17}$ between 1995 and 2004. During the sample period, a total of 1,112,777 patients were hospitalized due to CAD. Excluding those who were hospitalized

\footnotetext{
${ }^{17}$ Diagnosis codes for CAD: ICD-9-CM 410x-414x.
} 
for the same diagnosis in the previous year, and repeated admission records within the same quarter, the final sample contains 714,088 CAD patients.

The analysis centers on two outcomes: an individual's incidence of CABG or PCI ${ }^{18}$ procedure within a three month period (a quarter) after admission for CAD; and the incidence of CABG or PCI procedure at any incumbent hospital within one quarter after admission for CAD. The first outcome is used to assess the response of per-patient demand for procedure to the entry of new cardiac surgery centers. The second outcome is used to identify how patient flow is redistributed from existing centers to new centers following entry. Table 1 presents the summary statistics of procedure incidences and surgical outcomes by patient severity. Patients with MediQual scores greater than or equal to 2 are identified as high-severity. More than half of hospitalized CAD patients in the study period received either a CABG or PCI procedure within 3 months after admission. Without adjusting for age, gender, and other individual factors, the lowseverity patients were more likely to undergo CABG and PCI procedures than the high-severity patients.

Figure 3 contrasts the trends of 3-month CABG and PCI rates between1995 and 2004, which are further divided into trends in markets where entry occurred versus markets where entry never occurred. These rates are expressed as the number of procedures per 1,000 new CAD patients in the study sample, and markets are defined as Hospital Service Area (HSA) ${ }^{19}$. As shown in Figure 3, markets that experienced entry had higher rates of CABG and PCI than markets that did not experience entry both before and after the 1996 CON repeal. Nevertheless, the average CABG rate gradually declined since 1997, despite the continuing entry of new surgery centers in these markets. In contrast, PCI diffused rapidly in both entry and no-entry

\footnotetext{
${ }^{18}$ Procedure codes for CABG: ICD-9-CM 3610-3619. Procedure codes for PCI: ICD-9-CM 3601, 3602, 3605, 3606, 3607, and 3609 .

${ }^{19}$ HSAs are groups of zip codes whose residents receive most of their hospitalizations from the hospitals in that area. There are 127 HSAs in Pennsylvania. Our market definition differs from Cutler et al. (2010), which used Hospital Referral Regions (HRRs). The use of HRRs can create measurement error of entrant market share because 7 out of 21 HRRs include areas of neighboring states, where we do not observe patient flows. Therefore, we use smaller geographic markets, the HSAs, to mitigate the boundary problem.
} 
markets, mirroring national trends that occurred with the introduction of stent technology during the mid-1990s (Epstein et al., 2011).

However, taken by itself Figure 3 does not necessarily provide evidence that free entry in the post-CON period explains the shifts in revascularization rates, since it does not distinguish between market effects and temporal effects due to technological change. Moreover, Figure 3 does not distinguish between market areas with different concentrations of entrants at different time points in time. To identify these effects we implement the empirical analysis described below.

\section{Empirical Framework}

\section{V.A. General Specification}

It is hypothesized that the entry of new cardiac surgery centers may lead to both demandaugmenting and business-stealing effects in the aftermath of the repeal of CON. To test for the demand-augmenting effect, we estimate changes in CABG and PCI incidences in local area where new entrants had a larger market share, relative to areas where they had low market share following the repeal of CON. Using the sample of first-time CAD patients, we estimate two alternative specifications of the regression model, (1a) and (1b). The more parsimonious equation (1a) captures the average effect of entry, similar to the baseline model in Barro et al.'s (2006) study of cardiac specialty hospitals ${ }^{20}$. Equation (1b) incorporates area-specific pre-existing trends to allow for identification of area trends attributable to CON deregulation. Finkelstein (2007) uses an analogous model in her study of Medicare implementation, referring to it as "differences-intrend". ${ }^{21}$ We specify both models as follows:

\footnotetext{
${ }^{20}$ While highly related to our study, Barro et al's analysis of entry into the CABG and PTCA markets focused more narrowly on specialty hospitals; they do not consider entry by general hospitals who open new revascularization centers. According to these authors only five specialty hospitals entered these markets nationally during their study period of 1996-1999. Their results showed that specialty hospitals tended to enter market area with a healthier mix of patients, thereby incurring lower costs.

${ }^{21}$ In our special case entrant market share forms the local impact variable to be interacted with trend. In Finkelstein's case, the time interacted impact variable is the percent of elderly individuals in a region
} 


$$
\begin{aligned}
Y_{i k h t}= & \alpha_{k} I\left(H S A_{k}\right)+\beta_{t} I\left(\text { year }_{t}\right)+\gamma\left(S_{k t} \cdot \text { Post }_{t}\right)+X_{i t}^{\prime} \eta+Z_{h t}^{\prime} \delta+\epsilon_{i k h t}, \\
Y_{i k h t}= & \alpha_{k} I\left(H S A_{k}\right)+\beta_{t} I\left(\text { year }_{t}\right)+\theta_{k}\left[I\left(H S A_{k}\right) \cdot t_{t}\right]+\gamma\left(S_{k t} \cdot \text { Post }_{t}\right)+X_{i t}^{\prime} \eta \\
& +Z_{h t}^{\prime} \delta+\epsilon_{i k h t},
\end{aligned}
$$

where the dependent variable $Y_{i k h t}$ equals one if patient $i$ from market $k$ admitted to hospital $h$ at time $t$ received CABG or PCI procedure within a period one quarter after admission to a hospital for CAD; $I\left(H S A_{k}\right)$ are market fixed effects; $I\left(\right.$ year $\left._{t}\right)$ are year fixed effects, $X_{i t}^{\prime}$ is a vector of patient characteristics, $Z_{h t}^{\prime}$ is a vector that controls for characteristics of the admitting hospital, and $\epsilon_{i k h t}$ is an error term. Standard errors are clustered by market area to account for any withinarea correlation.

In both models, $\gamma$ is the policy parameter of interest. In equation (1a), the corresponding variable of interest is defined as $S_{k t} \cdot$ Post $_{t}$, the interaction between the market share of new cardiac surgery centers in market $k$ at time $t$ and an indicator variable that equals 1 for years after the repeal of CON ( $t=1997 \ldots$ 2004). This interaction measures the extent to which area $k$ is exposed to entrants' market power at time $t$ during the post-policy period. Thus the coefficient $\gamma$ identifies the difference in per-patient demand for revascularization procedures in areas where entrant market share is relatively high. A positive $\gamma$ implies that entry of new surgery centers expands market demand for CABG or PCI procedure by CAD patients. If $\gamma$ is zero, the total demand for $\mathrm{CABG}$ or PCI does not increase following the entry.

While informative about average entry effects, the parsimonious model $\gamma$ may reflect a general time trend in procedure rates that began prior to the repeal of CON in 1996, independent of the policy itself (by definition, entrant share equals zero for all markets until 1997). To address

without private insurance in 1963, the year in which Medicare was introduced. Thus in our case, the impact variable varies longitudinally as well as across areas. 
this concern, equation (1b) imposes a area-specific linear trend $\left[I\left(H S A_{k}\right) \cdot t_{t}\right]^{22}$ and allows for a shift in trend after the repeal of CON that varies with the entrants market share $\left(S_{k t} \cdot\right.$ Post $\left._{t}\right)$. Here, the coefficient $\gamma$ indicates the differential shift from pre-existing trends experienced by markets with higher entrant share relative to markets with zero entrant share.

Next, we attempt to identify business stealing behavior. Accordingly, new cardiac surgery centers have an incentive to draw patients away from existing hospitals even if total demand has expanded. To test for this effect, we simply re-estimate equations (1a) and (1b), by replacing the previous dependent variable with a binary variable that equals one if the patient received CABG or PCI procedure at any incumbent hospitals within one quarter of admission for CAD $\left(V_{i k h t}\right)$. Thus we estimate:

$$
\begin{aligned}
V_{i k h t}= & \alpha_{k} I\left(H S A_{k}\right)+\beta_{t} I\left(\text { year }_{t}\right)+\gamma\left(S_{k t} \cdot \text { Post }_{t}\right)+X_{i t}^{\prime} \eta+Z_{h t}^{\prime} \delta+\epsilon_{i k h t}, \\
V_{i k h t}= & \alpha_{k} I\left(H S A_{k}\right)+\beta_{t} I\left(\text { year }_{t}\right)+\theta_{k}\left[I\left(H S A_{k}\right) \cdot t_{t}\right]+\gamma\left(S_{k t} \cdot \text { Post }_{t}\right)+X_{i t}^{\prime} \eta+ \\
& Z_{h t}^{\prime} \delta+\epsilon_{i k h t} .
\end{aligned}
$$

If higher entrant market share leads, on average, to a decrease in patient demand at incumbent hospitals, then a negative value for coefficient $\gamma$ would be expected. On the other hand, if entrant hospitals create new demand from the potential pool of patients such that the incumbent hospitals' demand is not reduced, we would expect $\gamma$ to approximately equal zero. A positive $\gamma$ may reflect either a spillover of demand-augmentation from entrant hospitals to all hospitals, or strategic behavior on the part of incumbent hospitals whereby they increase procedure volume in order to deter further entry (Dafny, 2005).

All of the models we estimate include patient characteristics and hospital traits. $X_{i t}^{\prime}$

\footnotetext{
${ }^{22}$ The trend variable $t_{t}=1, \ldots, 10$ for $t=1995, \ldots, 2004$.
} 
includes indicator variables for age $(50-59,60-69,70-79,80$ or older; 49 or younger is the omitted group), race (White, Black, Asian; omitted group is other races), gender, urban residence, MediQual severity score (1, 2, 3, and 4; omitted group is 0 ), admission status (emergency admission and transferred admission), insurance type (Medicare and Medicaid) and major clinical indications at admission (cardiogenic shock, hypertension, dialysis, heart failure, renal failure, and acute myocardial infarction). We also include in $X_{i t}^{\prime}$ a continuous variable for the annual percentage of HMO enrollees in the patient's county of residence, in order to control for the potential impact of HMO penetration on procedure use (Town and Vistnes 2001; Miller and Luft $1997)^{23}$

The vector $Z_{h t}^{\prime}$ includes the indicator variables for the hospital's bed capacity (200 beds to 400 beds and $>400$ beds; omitted group is $<200$ beds), teaching status, whether it is not-forprofit, and whether it belongs to a health care system. In addition, the literature on volumeoutcome relationship suggests that hospitals with a higher volume of a particular surgical procedure tend to achieve better patient outcomes (Birkmeyer et al. 2002; Halm et al. 2002; Shanhian and Normand 2003) $)^{24}$. To control for volume effects, the vector $Z_{h t}^{\prime}$ also includes two indicators of high-volume CABG hospital and PCI hospital, based on the number of cases performed at the hospital in the previous year. The cut-off values are 200 cases for CABG and 400 cases for PCI, following the recommendation by the ACC/AHA guidelines (Smith et al., 2001). Descriptive statistics for patient and hospital characteristics are reported in Table A-1 of the Appendix.

Finally, we estimate the extent to which the effect of entry on utilization and business varies with patient risk. In particular, we hypothesized that business stealing would be more concentrated among low risk patients, both because they are potentially more profitable from the

\footnotetext{
${ }^{23}$ To further test the potential confounding influence of HMOs on procedure use, we repeat the analyses on the Medicare sample only. See Section VI.B. for details.

${ }^{24}$ Economists have questioned whether such volume effects should be taken as evidence of "learning-bydoing" or quality. For instance, Gaynor et al. (2005) suggest that economies of scale and selection of low risk patients explain better outcomes at high-volume hospitals.
} 
perspective of the hospital, and because low risk-patients are more likely to value entrants as acceptable substitutes for established providers (Capps et al., 2003). To test this hypothesis, we estimate another variant of the above equations, allowing for heterogeneous demand responses of high-severity versus low-severity patients. Specifically, focusing on the full interrupted time series design from equations ( $1 b)$ and $(2 b)$, we add interactions between a patient's on-admission illness severity and the post-trend as follows:

$$
\begin{aligned}
Y_{i k h t} & =\alpha_{k} I\left(H_{i k h t} A_{k}\right)+\beta_{t} I\left(\text { year }_{t}\right)+\theta_{k}\left[I\left(H S A_{k}\right) \cdot t_{t}\right]+\gamma_{1}\left[I\left(M_{i t}=0\right) \cdot S_{k t} \cdot \text { Post }_{t}\right] \\
& +\gamma_{2}\left[I\left(M_{i t}=1\right) \cdot S_{k t} \cdot \text { Post }_{t}\right]+\rho_{1} M_{i t}+\rho_{2}\left(M_{i t} \cdot \text { Post }_{t}\right)+X_{i t}^{\prime} \eta+Z_{h t}^{\prime} \delta+\epsilon_{i k h t},
\end{aligned}
$$

where $I(\cdot)$ is an indicator function, $M_{i t}$ equals 0 if the patient's MediQual severity score is below 2, and $M_{i t}$ equals 1 if the patient's MediQual severity score is equal to or greater than 2 . To control for any systematic shift in procedure incidences for the two patient groups in the postpolicy period, we include an interaction between the illness-severity indicators and Post $_{t}$. Coefficients $\gamma_{1}$ and $\gamma_{2}$ separately capture the effects of entry on low- and high-severity patients. In the demand-augmenting analysis, a difference in the magnitudes of estimated $\gamma_{1}$ and $\gamma_{2}$ provides evidence that hospitals selectively expand treatment among patients with different levels of illness severity. In the business-stealing analysis, the $\gamma_{1}$ estimate is expected to be smaller than $\gamma_{2}$ because relatively healthier patients are likely to be disproportionately attracted from incumbent centers to new cardiac surgery centers.

\section{V.B. Robustness to Alternative Specifications}

To check the robustness of our main results, we reestimated equation (3) in several ways, each time using an alternative definition of a key variable. Among these are an alternative classification of incumbent and entrant hospitals, two alternative measures of patient severity 
groupings other than the severity measure previously described, the addition of a supply-side variable (surgeons), and finally a reestimation using Medicare patient sample. Further detail is provided in section VI along with a brief discussion of the results.

\section{V.C. Measuring Entrants’ Market Share}

One issue we have not yet addressed in relation to the patient-level equations (1) - (3) is our definition of market share. Entrant's market share is the aggregate of patient-level probabilities of treatment at entry hospitals in the market area. There are two ways to assign market share to each patient. One is based on where the patient was admitted, and the other is based on where the patient lives. The former is susceptible to endogeneity bias because the patient's choice of hospital may depend on unobservable factors that correlate with the patient treatment decision. For instance, patients with unobservablely high valuations of cutting-edge care may prefer to be admitted to teaching hospitals located in urban areas where entrant share is higher. To address this, we define market share by the patient's area of residence.

Even so, measuring entrant share with actual treatment volume can lead to bias because hospitals' investment in new capacity, e.g. entry, is guided by potential demand and revenue in the relevant market (Wedig et al. 1989; Chernew et al. 2002; Dafny 2005). Although the use of area fixed effects may alleviate this concern, the potential for unobserved heterogeneity remains. To address this, we construct predicted hospital choice equations using the method by Kessler and McClellan (2000) and Gowrisankaran and Town (2003), whereby exogenous distances to hospitals in the patient's geographic area enter as instrumental variables. Further, following Kessler and McClellan (2000), we estimate hospital choice separately for CABG and PCI, and as noted above, sum up the probabilities of treatment at entrants by patient location rather than hospital location to obtain shares. The full estimation method is described in the Appendix.

Table 2 shows how entrant shares in CABG and PCI markets have changed during the freeentry period. As measured by predicted patient demands, the average CABG entrant share across 
all HSAs increased from $3.2 \%$ to $29.6 \%$, and the PCI entrant share increased from $3.5 \%$ to $33.1 \%$, from 1997 to 2004 . The actual entrant market shares are slightly smaller than the predicted entrant market shares, meaning that patients are more likely to choose entrant hospitals if their decisions are based only on exogenous factors. By either measure, the entrant share distributions are highly skewed to the right, with more than half of the markets having extremely small entrant share.

To deal with the possibly non-linear relationship between entrant share and outcome variables, we categorize markets into zero-, low-, and high-entrant share groups. The reference group is zero-entrant share group, which contains all markets in 1995-96 and most markets in 1997-98. The markets with non-zero entrant shares are divided into two groups with the median entrant share value as the cutoff; this is roughly 12 percent and 14 percent for CABG and PCI markets, respectively. In the CAD patients sample, approximately $28 \%, 37 \%$, and $35 \%$ of all patients fall into each category.

\section{Results}

\section{VI.A. Main Results}

Table 3 reports the results of eight sets of logistic regressions where the dependent variables is the individual's likelihood of having CABG (PCI) at any hospital (demandaugmenting), and at any incumbent hospital (business-stealing), within three months of being diagnosed with coronary artery disease (CAD). Coefficient estimates are converted to represent percentage changes in the value of the dependent variables.

Panel A shows the estimates of coefficients $\gamma^{\prime} s$ on the interaction term $\left(S_{k t} \cdot\right.$ Post $\left._{t}\right)$ in our parsimonious specifications in equations (1a) and (2a). Results in columns (1) and (2) of Panel A suggest that while entry with low entrant share did not have a significant impact on the incidence of revascularization, entry with high entrant share was associated with significantly

higher CABG and PCI incidences after the CON repeal. Columns (3) and (4) suggest that for both 
procedures, there was a concomitant business-stealing effect with the incidence of revascularization declining significantly at incumbent hospitals in high entrant share areas.

Panel B estimates equations (1b) and (2b), which control for the differential growth of procedure rates in across HSAs before the policy took effect. We again find a significant demandaugmenting effect on $\mathrm{CABG}$, while such effect on PCI appears to be absorbed by the areaspecific time-trends. In column (1), the $\gamma$ coefficients imply a 0.3 and 0.4 percentage point change in the likelihood of receiving $\mathrm{CABG}$, for low and high entrant share markets, respectively. Transformed into odds ratios, these estimates suggest that on average, in the post policy period CAD patients in markets with low and high entrant shares were respectively 7.6 to 10.9 percent more likely to undergo CABG, compared with patients in zero-entrant share markets. Consistent with Panel A, results in column (3) show that patients located in areas with higher entrant shares were less likely to receive $\mathrm{CABG}$ at incumbent hospitals compared to patients in zero entrant share markets, although the size of the effect was small and statistically insignificant. Lastly, the significantly negative estimates of $\gamma$ coefficients in column (4) indicate that market entry led to a sizable business-stealing effect in the PCI markets. The corresponding odds ratios suggest that on average, incumbent hospitals lost 9.9 to 14.1 percent of their PCI patients as a consequence of business-stealing.

Using estimates from equations ( $1 b)$ and (2b), we calculate the regression-adjusted probability of receiving cardiac revascularization procedures, and plot the time-series of the average regression-adjusted procedure rates in Figures 4 and 5. For each procedure, we separately plot the trends for areas with zero entrant share and for areas with non-zero (low and high) entrant share. By definition, entrant share equals zero in all market areas prior to 1997. Figure 4 shows that the average $\mathrm{CABG}$ rate in areas with zero entrant share declined steadily between 1997 and 2004. In contrast, the average $\mathrm{CABG}$ rate in areas with low and high entrant share followed the pre-CON trend rising until 2000, but then declined at a slower rate than areas with zero entrant share. In figure 5, while the average PCI rate showed an upward trend in both types of markets, it 
increased slightly more rapidly in areas with low and high entrant share, especially toward the end of the sample period. These time-series plots provide further evidence of demand-augmenting effects associated with market entry.

Table 4 reports the estimation results from equation (3), which investigates the extent to which entry had different impacts on low- and high-severity patients. Overall, high-severity patients are more likely to receive $\mathrm{CABG}$, and less likely to receive PCI, than low-severity patients. Comparing the estimated coefficients $\gamma_{1}$ and $\gamma_{2}$ in the first two columns, we find that the expansion of $\mathrm{CABG}$ procedures mainly targeted sicker patients, while healthier patients may have experienced a modestly higher incidence of PCI following entry. Specifically, entry led to a sizable increase of 1.8 - 3.4 percentage points (Column 1) in the likelihood of CABG procedures $(\Delta$ odds ratio $=11.6-23.8$ percent $)$ among high-severity patients, and an increase of 1.1 percentage points (Column 2) in the likelihood of PCI procedures $(\Delta$ odds ratio $=6.7$ percent $)$ among low-severity patients, during the post-policy period.

Results in Column (3) show that entrant share had a positive impact on high-severity patients, and a negative impact on low-severity patients, in their likelihood of receiving CABG at incumbent hospitals. These estimates suggest that low-severity patients tended to be shifted away from incumbents to new surgery centers. As shown in column (4), while entry had a negative effect on incumbents' volume of low-severity as well as high-severity PCI patients, such effect was relatively larger among low-severity patients. ${ }^{25}$ Therefore, we conclude that the estimates in columns (3) and (4) support the risk-allocation hypothesis, which predicts that new surgery centers are likely to attract disproportionately more low-severity patients from incumbent hospitals.

\section{VI.B. Alternative Specifications}

\footnotetext{
${ }^{25}$ Interpreted as changes in odds ratio, the estimated coefficients in Column (4) represent a decreased likelihood of undergoing PCI at incumbent hospitals by $11-17.3$ percent for low-severity patients, and 13.4 - 13.7 percent for high-severity patients in non-zero entrant share markets.
} 
To examine the stability of the main effects (the $\gamma$ coefficients), we changed the definition of entrants from cardiac surgery centers to those that were "in the market" for only three years or less as of the repeal of CON in 1996; concomitantly, entrants with more than three consecutive years of market presence as of 1997 were reassigned as incumbents. Switching to the 3-year definition caused the number of entrants in the data to fall from 28 to 13 in 2004; the new threshold for high entrant share is roughly 4 percent compared with 12 percent under the original definition. This repeated analysis also provides answers to additional questions of interest. Previously, identification came from variation in the "cumulative" entrant market share within markets. To this extent, the estimated coefficients revealed the long-term effects of entry since the repeal of CON. Instead we now examine short-run effects: Did the demand for revascularization grow immediately after new cardiac surgery centers entered the market? Was the negative demand shock on incumbent hospitals stronger in the short term?

Results are reported in Table 5. The signs of coefficients are generally consistent with those in Table 4. Estimates in the first two columns indicate that in markets with higher 3-year entrant shares, high-severity patients are more likely to undergo CABG, while low-severity patients' revascularization rates were not much affected. The significantly negative coefficient estimates in columns (3) and (4) indicate the presence of business-stealing in the short run. The relative magnitudes of estimated $\gamma_{1}$ and $\gamma_{2}$ further suggest that incumbent hospitals lost a larger proportion of low-severity patients immediately following the entry of new surgery centers.

Tables 6 presents estimates for the effects of entry on the likelihood of CABG and PCI procedures based on various alternative specifications. Column (1) of Table 6 reproduces the baseline results. Columns (2) and (3) of Table 6 explore alternative measures of patient illness severity. In column (2), we follow Dranove et al. (2003) and Kessler and Geppert (2005) to define high-severity patients as those who experienced hospitalization in the year prior to their CAD. This definition identifies $23.1 \%$ of the sample as high-severity patients. In column (3), a patient is identified as high-severity if her Elixhauser comorbidity score was greater than or equal 
to $2 .^{26}$ In the study sample, the Elixhauser comorbidity score ranges from 0 to 7 , and the correlation between the MediQual score and Elixhauser score is 0.13 . The estimates in columns (2) and (3) are remarkably similar to the baseline results and show no evidence that our results are sensitive to alternative definitions of patient severity.

Column (4) investigates whether the differential revascularization rates between zero and non-zero entrant share markets were driven by the supply of cardiac surgeons. In particular, entry by new cardiac surgery centers may have attracted more cardiac surgeons, imposing greater financial stress on incumbent surgeons and thus providing incentives for them to perform more surgeries. The number of CABG surgeons increased from 248 in 1995 to 284 in 2001, and then dropped to 231 in 2004, while the number of PCI surgeons increased steadily from 570 in 1995 to 684 in 2004. If such a change causes increased procedure referrals, it may be picked up by the estimated effects of entrant market share. To examine this issue, we control for the number of CABG surgeons and the number of cardiologists performing PCI in each patient's county of residence. As shown in column (4), results are robust to this additional control.

Finally, we examine the possibility that our results are driven by unobserved influence of insurance plans. As mentioned earlier, one particular concern is the potential confounding influence of HMOs on private insurance patients. On the one hand, HMOs are less likely to encourage hospitalization and expensive revascularization procedures. On the other hand, HMOs' selective contracting has enhanced price competition successfully among hospitals and lowered hospital prices, making high-cost procedures more affordable (Town and Vistnes 2001; Miller and Luft 1997). While we controlled for patient payer type and county-level HMO penetration rate, there may still be systematic differences between private and public insurance plans that affected patients' choice of treatment and hospital. To test this, we repeat the analyses on the Medicare-only sample as shown in column (5). Estimates in column (5) are generally unchanged

\footnotetext{
${ }^{26}$ The Elixhauser risk measure includes 30 categories of comorbid illness, which are identified using ICD9-CM diagnosis codes (Elixhauser et al. 1998).
} 
from the baseline results. Perhaps the only exception is in the last panel, where the estimated business-stealing effects among high-severity PCI Medicare patients appeared to be larger than the baseline estimates. Overall, our general findings are unaffected by these specification tests.

\section{Conclusion}

The majority of hospital markets in the United States currently operate under statemandated certificate-of-need regulation which impedes market entry. Concerns over anticompetitive effects and adverse impacts on the availability of services to consumers led a number of states to repeal CON regulation in recent years. Previous research has focused primarily on the efficiency consequences of $\mathrm{CON}$, generally finding no significant costdifferences between $\mathrm{CON}$ and non-CON states, with little evidence provided on volume effects (e.g. Ho and Ku-Goto, 2013). Moreover, little has been previously known about the degree to which deregulation correlates with market entry, or the effect of unimpeded entry has on the incidence and flow of services in these markets. In this study, we aim to fill the gap by exploring the impacts of post-deregulation hospital entry on the use of major cardiac procedures in Pennsylvania, a state which experienced rapid market entry after the repeal of its CON in 1996.

Consistent with previous studies, we find that the removal of entry restrictions in Pennsylvania was associated with a substantial increase in the number of hospitals performing cardiac revascularization procedures, coupled with an overall downward trend in CABG, and an overall upward trend in the alternative procedure, PCI. Examining the role of entry by new cardiac surgery centers, we find that entry led to a significant increase in the likelihood of CABG, relative to trend, but it did not contribute to the increase in PCI after adjusting for patient traits, market characteristics, and area-specific trends. Our analyses show that the probability of receiving PCI specifically at incumbent hospitals decreased with market entry, suggesting a volume shift from incumbents to entrants, a phenomenon referred to as business stealing. Results of our analyses further indicate that entry by new cardiac surgery centers tended to sort high- 
severity patients into the more invasive $\mathrm{CABG}$ procedure and low-severity patients into the less invasive PCI procedures. Regarding risk-allocation among hospitals, we find evidence that entry shifted disproportionate volume of low-severity patients from incumbent hospitals to entrants.

While our analysis on impacts of market level entry and entrant concentration on procedure likelihood and trends are novel, our results echo findings from studies in related literature which suggest that hospital entry contributed to increased quantity of services, as observed in market aggregates (Abraham et al. 2007; Mitchell 2007). Our results on business stealing by entrants parallel those of Huckman (2006), which show that acquiring hospital chains tend to draw volume from target hospitals. The finding that entrant hospitals tended to disproportionately attract low-severity patients away from incumbent hospitals is consistent with Barro et al. (2006), thereby suggesting that the risk-allocation effect of entry is not unique to specialty hospitals. Finally, focusing on per unit costs of hospitalizations, Kessler and Geppert (2005) show that low- and high- risk patients are sorted more efficiently into low intensity and high intensity care when markets are competitive.

As for welfare implications for policies, such as $\mathrm{CON}$, that are designed to remove barrier entries in hospitals markets, our results are mixed: on the one hand, free-entry may lead to improved access to care rather than business stealing for CABG procedures; on the other hand, there is significant empirical evidence in favor of welfare-reducing business-stealing for PCI procedures. Moreover, free-entry improves the match between underlying medical risk and treatment intensity, potentially improving quality of care and hence welfare enhancing. These findings underscore the importance of considering strategic responses by hospitals when evaluating the impact of free entry into hospital markets when regulatory barriers to entry are rescinded.

In conclusion, our analysis complements and extends previous studies by exploring the interaction of $\mathrm{CON}$ deregulation and market entry. Moreover, building on an empirical analysis 
of patient heterogeneity and hospital preference, we allow the impact of the policy to vary by local market area, and thus provide a more nuanced understanding of the responses to entry as measured by patient flows. Future research might apply our analytical framework to efficiency measures such as costs or patient outcomes. 


\section{References}

Abraham, J. M., Gaynor, M., \& Vogt, W. B. (2007). Entry and Competition in Local Hospital Markets. Journal of Industrial Economics, 55(2), 265-288.

American Health Planning Association. 2011. American Health Planning Association National Directory. Retrieved from http://www.ahpanet.org/national_directory.html

Barro, J. R., Huckman, R. S., \& Kessler, D. P. (2006). The Effects of Cardiac Specialty Hospitals on the Cost and Quality of Medical Care. Journal of Health Economics, 25(4), 702-721.

Birkmeyer, J. D., Siewers, A. E., Finlayson, E. V. A., Stukel, T. A., Lucas, F. L., Batista, I., et al. (2002). Hospital Volume and Surgical Mortality in the United States. New England Journal of Medicine, 346(15), 1128-1137.

Brekke, K. R., Nuscheler, R., \& Rune Straume, O. (2006). Quality and Location Choices Under Price Regulation. Journal of Economics \& Management Strategy, 15(1), 207-227.

Bresnahan, T. F., \& Reiss, P. C. (1990). Entry in Monopoly Markets. Review of Economic Studies, 57(4), 531-553.

Bresnahan, T. F., \& Reiss, P. C. (1991). Empirical Models of Discrete Games. Journal of Econometrics, 48(1-2), 57-81.

Burns, L. R., David, G., \& Helmchen, L. A. (2009). Effective Responses to Market Entry by Specialty Hospitals and Ambulatory Surgery Centers. Philadelphia, PA.

Calem, P. S., \& Rizzo, J. A. (1995). Competition and Specialization in the Hospital Industry: An Application of Hotelling's Location Model. Southern Economic Journal, 1182-1198.

Capps, C., \& Dranove, D. (2004). Hospital Consolidation and Negotiated PPO Prices. Health Affairs, 23(2), 175-181.

Capps, C., Dranove, D., \& Satterthwaite, M. (2003). Competition and Market Power in Option Demand Markets. The Rand Journal of Economics, 34(4), 737-763.

Chernew, M., Gowrisankaran, G., \& Fendrick, A. M. (2002). Payer Type and the Returns to Bypass Surgery: Evidence from Hospital Entry Behavior. Journal of Health Economics, 21(3), 451-474.

Cram, P., Rosenthal, G. E., \& Vaughan-Sarrazin, M. S. (2005). Cardiac Revascularization in Specialty and General Hospitals. New England Journal of Medicine, 352(14), 1454-1462.

Cutler, D. M., \& Huckman, R. S. (2003). Technological Development and Medical Productivity: The Diffusion of Angioplasty in New York State. Journal of Health Economics, 22(2), 187-217.

Cutler, D. M., Huckman, R. S., \& Kolstad, J. T. (2010). Input Constraints and the Efficiency of Entry: Lessons from Cardiac Surgery. American Economic Journal: Economic Policy, 2(1), 51-76. 
Dafny, L. S. (2005). Games Hospitals Play: Entry Deterrence in Hospital Procedure Markets. Journal of Economics \& Management Strategy, 14(3), 513-542.

Dranove, D., Kessler, D., McClellan, M., \& Satterthwaite, M. (2003). Is More Information Better? The Effects of "Report Cards" on Health Care Providers. [Article]. Journal of Political Economy, 111(3), 555-588.

Elixhauser, A., Steiner, C., Harris, D. R., \& Coffey, R. M. (1998). Comorbidity Measures for Use with Administrative Data. Medical care, 36(1), 8-27.

Ellison, G., \& Ellison, S. F. (2011). Strategic Entry Deterrence and the Behavior of Pharmaceutical Incumbents Prior to Patent Expiration. American Economic Journal: Microeconomics, 3(1), 1-36.

Epstein, A. J., Polsky, D., Yang, F., Yang, L., \& Groeneveld, P. W. (2011). Coronary Revascularization Trends in the United States, 2001-2008. JAMA: The Journal of the American Medical Association, 305(17), 1769-1776.

Finkelstein, A. (2007). The Aggregate Effects of Health Insurance: Evidence from the Introduction of Medicare. The Quarterly Journal of Economics, 122(1), 1-37.

Gaynor, M., Seider, H., \& Vogt, W. B. (2005). The Volume-Outcome Effect, Scale Economies, and Learning-by-Doing. The American Economic Review, 95(2), 243-247.

Gaynor, M., \& Vogt, W. B. (2003). Competition among Hospitals. The Rand Journal of Economics, 34(4), 764-785.

Gowrisankaran, G., \& Town, R. J. (2003). Competition, Payers, and Hospital Quality. Health Services Research, 38(6p1), 1403-1422.

Halm, E. A., Lee, C., \& Chassin, M. R. (2002). Is Volume Related to Outcome in Health Care? A Systematic Review and Methodologic Critique of the Literature. Annals of Internal Medicine, 137(6), 511-520.

Ho, K. (2006). The welfare Effects of Restricted Hospital Choice in the US Medical Care Market. Journal of Applied Econometrics, 21(7), 1039-1079.

Ho, V. (2006). Does Certificate of Need Affect Cardiac Outcomes and Costs? International Journal of Health Care Finance and Economics, 6(4), 300-324.

Ho, V., \& Ku-Goto, M.-H. (2013). State Deregulation and Medicare Costs for Acute Cardiac Care. Medical Care Research and Review, 70(2), 185-205.

Ho, V., Ku-Goto, M.-H., \& Jollis, J. G. (2009). Certificate of Need (CON) for Cardiac Care: Controversy over the Contributions of CON. Health Services Research, 44(2p1), 483-500.

Hotelling, H. (1929). Stability in Competition. The Economic Journal, 39(153), 41-57.

Huckman, R. S. (2006). Hospital Integration and Vertical Consolidation: An Analysis of Acquisitions in New York State. Journal of Health Economics, 25(1), 58-80. 
Kessler, D. P., \& Geppert, J. J. (2005). The Effects of Competition on Variation in the Quality and Cost of Medical Care. Journal of Economics \& Management Strategy, 14(3), 575589.

Kessler, D. P., \& McClellan, M. B. (2000). Is Hospital Competition Socially Wasteful? Quarterly Journal of Economics, 115(2), 577-615.

Lezzoni, L. I., \& Moskowitz, M. A. (1988). A Clinical Assessment of Medis-Groups. [doi: 10.1001/jama.1988.03410210071039]. JAMA: The Journal of the American Medical Association, 260(21), 3159-3163.

Longwell, C. B., \& Steele Jr, J. T. (2011). Rise and Fall of Certificate of Need in Pennsylvania: An Experiment in Health Care Planning and the Role of the Commonwealth Court, The. Widener LJ, 21, 185.

Luft, H. S., Robinson, J. C., Garnick, D., Maerki, S. C., \& McPhee, S. J. (1986). The Role of Specialized Clinical Services in Competition Among Hospitals. Inquiry, 23(spring), 8394.

Magid, D. J., Calonge, B. N., Rumsfeld, J. S., Canto, J. G., Frederick, P. D., Every, N. R., et al. (2000). Relation Between Hospital Primary Angioplasty Volume and Mortality for Patients with Acute MI Treated With Primary Angioplasty vs Thrombolytic Therapy. JAMA: The Journal of the American Medical Association, 284(24), 3131-3138.

Mankiw, N. G., \& Whinston, M. D. (1986). Free Entry and Social Inefficiency. RAND Journal of Economics, 17(1), 48-58.

Mcfadden, D. (1973). Conditional Logit Analysis of Qualitative Choice Behavior. Frontiers in econometrics.

Miller, R. H., \& Luft, H. S. (1997). Does Managed Care Lead to Better or Worse Quality of Care? Health Affairs, 16(5), 7-25.

Mitchell, J. M. (2007). Utilization Changes Following Market Entry by Physician-owned Specialty Hospitals. Medical Care Research and Review, 64(4), 395-415.

Nallamothu, B. K., Young, J., Gurm, H. S., Pickens, G., \& Safavi, K. (2007). Recent Trends in Hospital Utilization for Acute Myocardial Infarction and Coronary Revascularization in the United States. The American Journal of Cardiology, 99(6), 749-753.

Popescu, I., Vaughan-Sarrazin, M. S., \& Rosenthal, G. E. (2006). Certificate of Need Regulations and Use of Coronary Revascularization After Acute Myocardial Infarction. [doi: 10.1001/jama.295.18.2141]. JAMA, 295(18), 2141-2147.

Robinson, J. L., Nash, D. B., Moxey, E., \& O'Connor, J. P. (2001). Certificate of Need and the Quality of Cardiac Surgery. American Journal of Medical Quality, 16(5), 155-160.

Serruys, P. W., Morice, M.-C., Kappetein, A. P., Colombo, A., Holmes, D. R., Mack, M. J., et al. (2009). Percutaneous Coronary Intervention versus Coronary-Artery Bypass Grafting for Severe Coronary Artery Disease. New England Journal of Medicine, 360(10), 961-972. 
Shahian, D. M. (2004). Improving Cardiac Surgery Quality-Volume, Outcome, Process? The Journal of the American Medical Association, 291(2), 246-248.

Sharamitaro, A., \& Drew, C. (2011). Health Care Reform: Impact on Hospitals. Health Capital, 4.

Smith, S. C., Dove, J. T., Jacobs, A. K., Kennedy, J. W., Kereiakes, D., Kern, M. J., et al. (2001). ACC/AHA Guidelines for Percutaneous Coronary Intervention (Revision of the 1993 PTCA Guidelines) - Executive Summary: A Report of the American College of Cardiology/American Heart Association Task Force on Practice Guidelines (Committee to Revise the 1993 Guidelines for Percutaneous Transluminal Coronary Angioplasty) Endorsed by the Society for Cardiac Angiography and Interventions. Circulation, 103(24), 3019-3041.

Town, R., \& Vistnes, G. (2001). Hospital Competition in HMO Networks. Journal of Health Economics, 20(5), 733-753.

Wedig, G. J., Hassan, M., \& Sloan, F. A. (1989). Hospital Investment Decisions and the Cost of Capital. The Journal of Business, 62(4), 517-537. 
Table 1 Sample Statistics of Patients

\begin{tabular}{lccc}
\hline & Overall & Low-Severity & High-Severity \\
Receiving CABG in one quarter & 0.231 & 0.257 & 0.203 \\
Receiving PCI in one quarter & 0.360 & 0.450 & 0.262 \\
Receiving CABG in one quarter at incumbent hospitals & 0.206 & 0.226 & 0.184 \\
Receiving PCI in one quarter at incumbent hospitals & 0.312 & 0.386 & 0.231 \\
Observations & 714,088 & 371,937 & 342,151 \\
\hline
\end{tabular}

Notes: The CAD sample includes patients who are admitted to a hospital with a new CAD diagnosis within 3 months after admission. High-severity patients are defined as those with MediQual scores greater than or equal to 2 . 
Table 2 The Distribution of Predicted and Actual Entrant Market Share

\begin{tabular}{|c|c|c|c|c|c|c|}
\hline Year & & Mean & Std. Dev. & Lower Quartile & Median & Upper Quartile \\
\hline & & \multicolumn{5}{|c|}{ Predicted Entrant Market Share } \\
\hline \multirow[t]{2}{*}{1997} & CABG & 0.032 & 0.091 & 0 & 0 & 0.003 \\
\hline & PCI & 0.035 & 0.093 & 0 & 0 & 0.005 \\
\hline \multirow[t]{2}{*}{2000} & CABG & 0.132 & 0.195 & 0.003 & 0.057 & 0.172 \\
\hline & PCI & 0.142 & 0.208 & 0.005 & 0.055 & 0.204 \\
\hline \multirow[t]{2}{*}{2004} & CABG & 0.296 & 0.302 & 0.048 & 0.193 & 0.471 \\
\hline & PCI & 0.331 & 0.311 & 0.054 & 0.232 & 0.551 \\
\hline \multirow[t]{3}{*}{ Overall } & CABG & 0.135 & 0.228 & 0.000 & 0.018 & 0.171 \\
\hline & PCI & 0.141 & 0.234 & 0.000 & 0.016 & 0.197 \\
\hline & & \multicolumn{5}{|c|}{ Actual Entrant Market Share } \\
\hline \multirow[t]{2}{*}{1997} & CABG & 0.026 & 0.093 & 0 & 0 & 0 \\
\hline & PCI & 0.026 & 0.091 & 0 & 0 & 0 \\
\hline \multirow[t]{2}{*}{2000} & CABG & 0.132 & 0.224 & 0 & 0.017 & 0.177 \\
\hline & PCI & 0.126 & 0.227 & 0 & 0.006 & 0.154 \\
\hline \multirow[t]{2}{*}{2004} & CABG & 0.272 & 0.320 & 0 & 0.125 & 0.449 \\
\hline & PCI & 0.302 & 0.326 & 0.02 & 0.176 & 0.504 \\
\hline \multirow[t]{2}{*}{ Overall } & CABG & 0.125 & 0.239 & 0 & 0 & 0.126 \\
\hline & PCI & 0.128 & 0.243 & 0 & 0 & 0.130 \\
\hline
\end{tabular}


Table 3 Effects of Entry on Procedure Incidences

\begin{tabular}{|c|c|c|c|c|}
\hline & $\begin{array}{l}\text { CABG in } 3 \text { months } \\
\text { at any hospital } \\
\text { (1) }\end{array}$ & $\begin{array}{l}\text { PCI in } 3 \text { months at } \\
\text { any hospital } \\
\text { (2) }\end{array}$ & $\begin{array}{l}\text { CABG in } 3 \text { months } \\
\text { at any incumbent } \\
\text { hospital } \\
\text { (3) }\end{array}$ & $\begin{array}{l}\text { PCI in } 3 \text { months at } \\
\text { any incumbent } \\
\text { hospital } \\
\text { (4) }\end{array}$ \\
\hline \multicolumn{5}{|c|}{ Panel A: Not controlling for HSA-specific time trend } \\
\hline \multirow[t]{2}{*}{ Low entrant share*Post } & 0.002 & 0.001 & -0.001 & -0.006 \\
\hline & {$[0.006]$} & [0.005] & {$[0.007]$} & {$[0.007]$} \\
\hline \multirow[t]{2}{*}{ High entrant share*Post } & $0.015 * * *$ & $0.02 * * *$ & $-0.015^{* *}$ & $-0.033 * * *$ \\
\hline & {$[0.005]$} & {$[0.006]$} & {$[0.006]$} & [0.009] \\
\hline \multicolumn{5}{|c|}{ Panel B: Controlling for HSA-specific time trend } \\
\hline \multirow[t]{2}{*}{ Low entrant share*Post } & $0.003 * *$ & -0.005 & -0.001 & $-0.016^{* * *}$ \\
\hline & {$[0.002]$} & {$[0.004]$} & {$[0.002]$} & {$[0.006]$} \\
\hline \multirow[t]{2}{*}{ High entrant share*Post } & $0.004 * * *$ & 0.008 & -0.002 & $-0.024 * * *$ \\
\hline & {$[0.002]$} & {$[0.006]$} & {$[0.002]$} & {$[0.009]$} \\
\hline Observations & 714,088 & 714,088 & 714,088 & 714,088 \\
\hline
\end{tabular}

Notes: Coefficient estimates are converted to represent percentage changes. All specifications patient and hospital characteristics, HSA fixed effects and year fixed effects. Standard errors, adjusted for correlation in residents in the same HSA over time, are reported in brackets. $* * * \mathrm{p}<.01$, $* * \mathrm{p}<.05, * \mathrm{p}<.10$ 
Table 4 Effects of Entry on Procedure Incidences by Patient Severity

\begin{tabular}{|c|c|c|c|c|}
\hline & $\begin{array}{c}\text { CABG in } 3 \text { months } \\
\text { at any hospital }\end{array}$ & $\begin{array}{l}\text { PCI in } 3 \text { months at } \\
\text { any hospital }\end{array}$ & $\begin{array}{c}\text { CABG in } 3 \text { months } \\
\text { at any incumbent } \\
\text { hospital }\end{array}$ & $\begin{array}{c}\text { PCI in } 3 \text { months at } \\
\text { any incumbent } \\
\text { hospital }\end{array}$ \\
\hline & (1) & (2) & (3) & (4) \\
\hline \multirow[t]{2}{*}{ High-severity } & $0.015 * *$ & $-0.073 * *$ & $0.017 * * *$ & $-0.066 * * *$ \\
\hline & {$[0.003]$} & {$[0.003]$} & {$[0.003]$} & {$[0.003]$} \\
\hline \multicolumn{5}{|c|}{ Effects of entry on low-severity patients } \\
\hline \multirow[t]{2}{*}{ Low entrant share*Post } & 0.003 & -0.006 & -0.004 & $-0.018 * * *$ \\
\hline & {$[0.006]$} & {$[0.004]$} & [0.006] & {$[0.006]$} \\
\hline \multirow[t]{2}{*}{ High entrant share*Post } & -0.001 & $0.011 *$ & $-0.017 * * *$ & $-0.030 * * *$ \\
\hline & [0.006] & {$[0.006]$} & {$[0.006]$} & {$[0.009]$} \\
\hline \multicolumn{5}{|c|}{ Effects of entry on high-severity patients } \\
\hline \multirow[t]{2}{*}{ Low entrant share*Post } & $0.018 * * *$ & -0.003 & $0.008 *$ & $-0.014 * *$ \\
\hline & {$[0.005]$} & {$[0.005]$} & {$[0.005]$} & {$[0.006]$} \\
\hline \multirow[t]{2}{*}{ High entrant share*Post } & $0.034 * * *$ & 0.004 & $0.014^{*}$ & -0.015 \\
\hline & {$[0.006]$} & {$[0.01]$} & {$[0.007]$} & {$[0.012]$} \\
\hline Observations & 714,088 & 714,088 & 714,088 & 714,088 \\
\hline
\end{tabular}


Table 5 Effects of Entry on Procedure Incidences by Patient Severity (Entrant $=$ Hospitals operating for 3 years or less)

\begin{tabular}{|c|c|c|c|c|}
\hline & $\begin{array}{c}\text { CABG in } 3 \text { months } \\
\text { at any hospital }\end{array}$ & $\begin{array}{l}\text { PCI in } 3 \text { months at } \\
\text { any hospital }\end{array}$ & $\begin{array}{c}\text { CABG in } 3 \text { months } \\
\text { at any incumbent } \\
\text { hospital }\end{array}$ & $\begin{array}{c}\text { PCI in } 3 \text { months at } \\
\text { any incumbent } \\
\text { hospital }\end{array}$ \\
\hline & $(1)$ & $(2)$ & $(3)$ & (4) \\
\hline \multirow{2}{*}{ High-severity } & $0.015 * * *$ & $-0.073 * * *$ & $0.016 * * *$ & $-0.07 * * *$ \\
\hline & {$[0.003]$} & {$[0.003]$} & {$[0.003]$} & {$[0.003]$} \\
\hline \multicolumn{5}{|c|}{ Effects of entry on low-severity patients } \\
\hline \multirow[t]{2}{*}{ Low entrant share*Post } & -0.001 & -0.005 & -0.005 & $-0.013 * *$ \\
\hline & {$[0.005]$} & [0.005] & {$[0.005]$} & [0.005] \\
\hline \multirow[t]{2}{*}{ High entrant share*Post } & 0.003 & 0 & $-0.021 * * *$ & $-0.039 * * *$ \\
\hline & [0.005] & [0.005] & {$[0.006]$} & [0.006] \\
\hline \multicolumn{5}{|c|}{ Effects of entry on high-severity patients } \\
\hline \multirow[t]{2}{*}{ Low entrant share*Post } & $0.012 * *$ & -0.005 & 0.008 & $-0.013 *$ \\
\hline & {$[0.005]$} & {$[0.005]$} & {$[0.005]$} & [0.007] \\
\hline \multirow[t]{2}{*}{ High entrant share*Post } & $0.02 * * *$ & 0.005 & -0.002 & $-0.027 * * *$ \\
\hline & {$[0.004]$} & [0.007] & {$[0.006]$} & {$[0.009]$} \\
\hline Observations & 714,088 & 714,088 & 714,088 & 714,088 \\
\hline
\end{tabular}


Table 6 Robustness Checks on CABG and PCI Procedure Incidence

\begin{tabular}{|c|c|c|c|c|c|}
\hline \multirow[b]{4}{*}{ Effects on low-severity patients } & Baseline & $\begin{array}{l}\text { Prior-year } \\
\text { expenditures }\end{array}$ & $\begin{array}{l}\text { Elixhauser } \\
\text { score }\end{array}$ & $\begin{array}{l}\text { Surgeon } \\
\text { supply }\end{array}$ & $\begin{array}{l}\text { Medicare } \\
\text { Sample } \\
\end{array}$ \\
\hline & $(1)$ & $(2)$ & (3) & $(4)$ & $(5)$ \\
\hline & \multicolumn{5}{|c|}{ CABG in 3 months at any hospital } \\
\hline & & & & & \\
\hline \multirow[t]{2}{*}{ Low entrant share*Post } & 0.003 & 0.008 & 0.004 & 0.003 & 0.003 \\
\hline & {$[0.006]$} & {$[0.005]$} & {$[0.006]$} & {$[0.006]$} & {$[0.006]$} \\
\hline \multirow[t]{2}{*}{ High entrant share*Post } & -0.001 & 0.011 & 0.001 & 0 & -0.005 \\
\hline & {$[0.006]$} & {$[0.006]$} & {$[0.006]$} & {$[0.006]$} & {$[0.007]$} \\
\hline \multicolumn{6}{|l|}{ Effects on high-severity patients } \\
\hline \multirow[t]{2}{*}{ Low entrant share*Post } & $0.018 * * *$ & $0.017 * * *$ & $0.019 * * *$ & $0.017 * * *$ & $0.017 * * *$ \\
\hline & {$[0.005]$} & {$[0.005]$} & {$[0.005]$} & {$[0.005]$} & {$[0.006]$} \\
\hline \multirow[t]{3}{*}{ High entrant share*Post } & $0.034 * * *$ & $0.028 * * *$ & $0.034 * * *$ & $0.035 * * *$ & $0.027 * * *$ \\
\hline & {$[0.006]$} & {$[0.006]$} & {$[0.007]$} & {$[0.007]$} & {$[0.007]$} \\
\hline & \multicolumn{5}{|c|}{ PCI in 3 months at any hospital } \\
\hline \multicolumn{6}{|l|}{ Effects on low-severity patients } \\
\hline \multirow[t]{2}{*}{ Low entrant share*Post } & -0.006 & -0.006 & -0.004 & -0.006 & -0.007 \\
\hline & {$[0.004]$} & {$[0.004]$} & {$[0.004]$} & {$[0.004]$} & {$[0.005]$} \\
\hline \multirow[t]{2}{*}{ High entrant share*Post } & $0.011 *$ & 0.008 & $0.013 *$ & $0.012 *$ & 0.01 \\
\hline & {$[0.006]$} & {$[0.006]$} & {$[0.007]$} & {$[0.006]$} & {$[0.007]$} \\
\hline \multicolumn{6}{|l|}{ Effects on high-severity patients } \\
\hline \multirow[t]{2}{*}{ Low entrant share*Post } & -0.003 & -0.001 & -0.008 & -0.003 & $-0.011 * *$ \\
\hline & {$[0.005]$} & {$[0.006]$} & {$[0.005]$} & {$[0.005]$} & {$[0.005]$} \\
\hline \multirow[t]{2}{*}{ High entrant share*Post } & 0.004 & $0.013 *$ & 0.001 & 0.005 & -0.005 \\
\hline & {$[0.01]$} & {$[0.007]$} & {$[0.008]$} & {$[0.01]$} & {$[0.009]$} \\
\hline
\end{tabular}

Effects on low-severity patients

\begin{tabular}{|c|c|c|c|c|c|}
\hline Low entrant share*Post & $\begin{array}{c}-0.004 \\
{[0.006]}\end{array}$ & $\begin{array}{c}0 \\
{[0.005]}\end{array}$ & $\begin{array}{c}-0.004 \\
{[0.006]}\end{array}$ & $\begin{array}{c}-0.004 \\
{[0.006]}\end{array}$ & $\begin{array}{c}-0.004 \\
{[0.006]}\end{array}$ \\
\hline High entrant share*Post & $\begin{array}{l}-0.017 * * * \\
{[0.006]}\end{array}$ & $\begin{array}{c}-0.008 \\
{[0.006]}\end{array}$ & $\begin{array}{l}-0.014 * * * \\
{[0.006]}\end{array}$ & $\begin{array}{l}-0.016^{* *} \\
{[0.006]}\end{array}$ & $\begin{array}{l}-0.021^{* * *} \\
{[0.007]}\end{array}$ \\
\hline \multicolumn{6}{|l|}{ Effects on high-severity patients } \\
\hline Low entrant share*Post & $\begin{array}{c}0.008 * \\
{[0.005]}\end{array}$ & $\begin{array}{c}0.009 * \\
{[0.005]}\end{array}$ & $\begin{array}{c}0.011 * * \\
{[0.005]}\end{array}$ & $\begin{array}{c}0.008 \\
{[0.005]}\end{array}$ & $\begin{array}{c}0.009 * \\
{[0.005]}\end{array}$ \\
\hline \multirow[t]{2}{*}{ High entrant share*Post } & $\begin{array}{c}0.014 * \\
{[0.007]}\end{array}$ & $\begin{array}{c}0.015^{*} \\
{[0.008]}\end{array}$ & $\begin{array}{c}0.011 \\
{[0.007]}\end{array}$ & $\begin{array}{c}0.014^{*} \\
{[0.008]}\end{array}$ & $\begin{array}{c}0.009 \\
{[0.007]}\end{array}$ \\
\hline & \multicolumn{5}{|c|}{ PCI in 3 months at any incumbent hospital } \\
\hline \multicolumn{6}{|l|}{ Effects on low-severity patients } \\
\hline Low entrant share*Post & $\begin{array}{l}-0.018^{* * *} * \\
{[0.006]}\end{array}$ & $\begin{array}{l}-0.018 * * * \\
{[0.006]}\end{array}$ & $\begin{array}{l}-0.016^{* * *} \\
{[0.006]}\end{array}$ & $\begin{array}{l}-0.018 * * * \\
{[0.006]}\end{array}$ & $\begin{array}{l}-0.016^{* * *} \\
{[0.006]}\end{array}$ \\
\hline High entrant share*Post & $\begin{array}{l}-0.030^{* * *} \\
{[0.009]}\end{array}$ & $\begin{array}{l}-0.027 * * * \\
{[0.008]}\end{array}$ & $\begin{array}{l}-0.029 * * * \\
{[0.009]}\end{array}$ & $\begin{array}{l}-0.029 * * * \\
{[0.009]}\end{array}$ & $\begin{array}{l}-0.028 * * * \\
{[0.009]}\end{array}$ \\
\hline \multicolumn{6}{|l|}{ Effects on high-severity patients } \\
\hline Low entrant share*Post & $\begin{array}{l}-0.014 * * \\
{[0.006]}\end{array}$ & $\begin{array}{c}-0.010 \\
{[0.008]}\end{array}$ & $\begin{array}{l}-0.017 * * * \\
{[0.006]}\end{array}$ & $\begin{array}{l}-0.014 * * \\
{[0.006]}\end{array}$ & $\begin{array}{l}-0.019 * * * \\
{[0.005]}\end{array}$ \\
\hline High entrant share*Post & $\begin{array}{c}-0.015 \\
{[0.012]}\end{array}$ & $\begin{array}{c}-0.007 \\
{[0.01]}\end{array}$ & $\begin{array}{c}-0.015 \\
{[0.01]}\end{array}$ & $\begin{array}{c}-0.014 \\
{[0.012]}\end{array}$ & $\begin{array}{l}-0.023^{* *} \\
{[0.01]}\end{array}$ \\
\hline Observations & 714,088 & 714,088 & 714,088 & 714,088 & 419,193 \\
\hline
\end{tabular}


Figure 1 Number of Cardiac Revascularization Centers in Pennsylvania 1993 - 2004

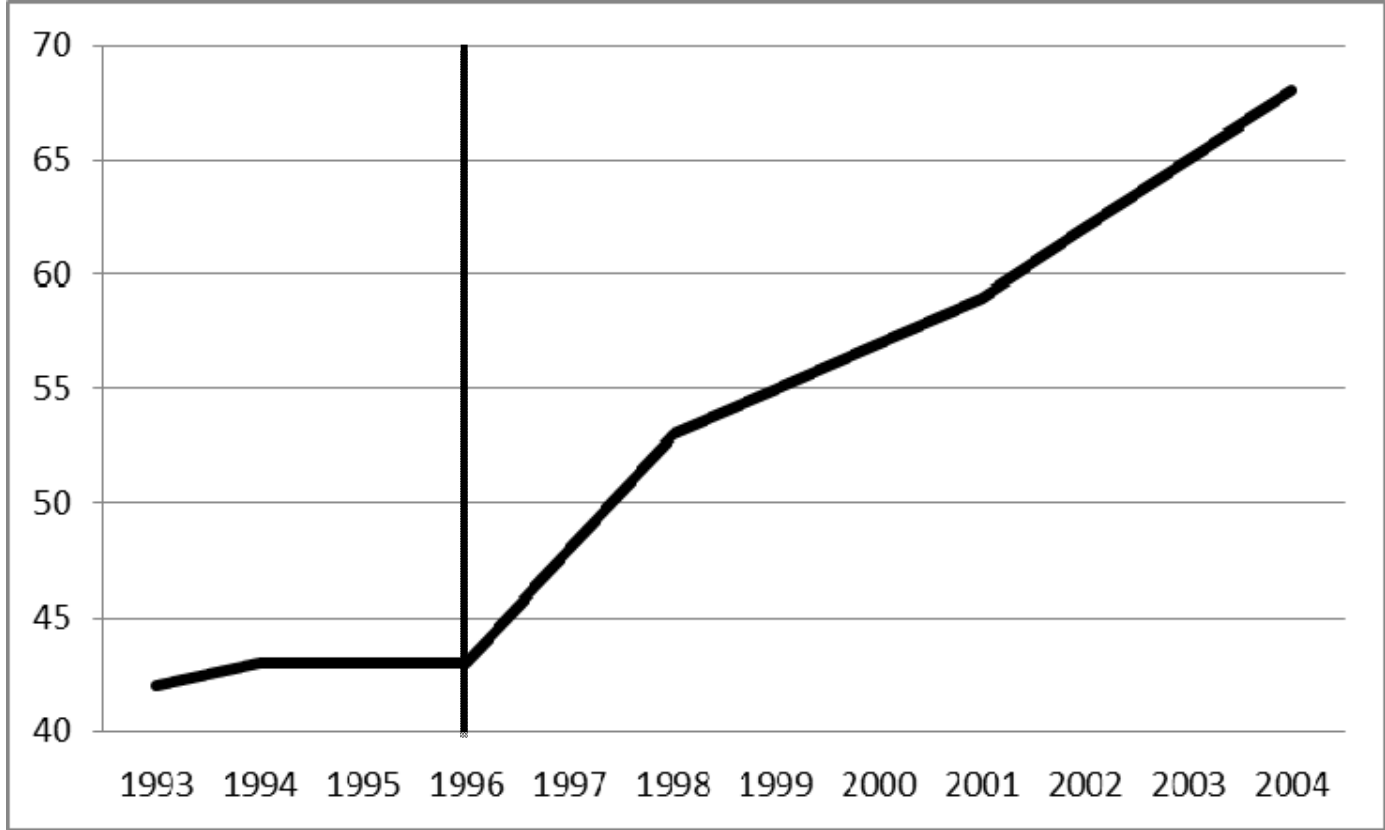

Figure 2 New CABG and PCI Centers in Pennsylvania 1997 - 2004

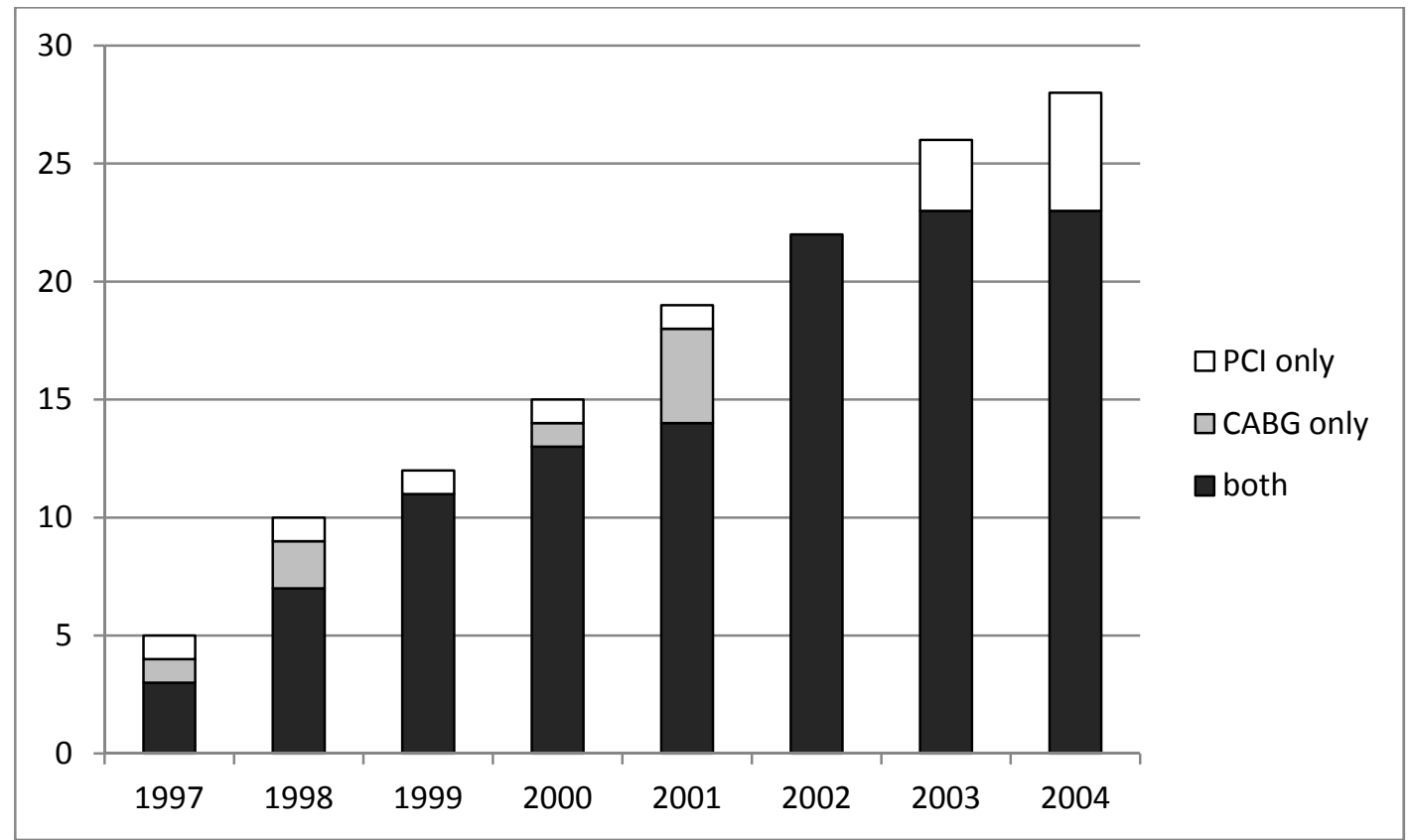


Figure 3 Unadjusted CABG and PCI Procedure Rates Among New CAD Patients

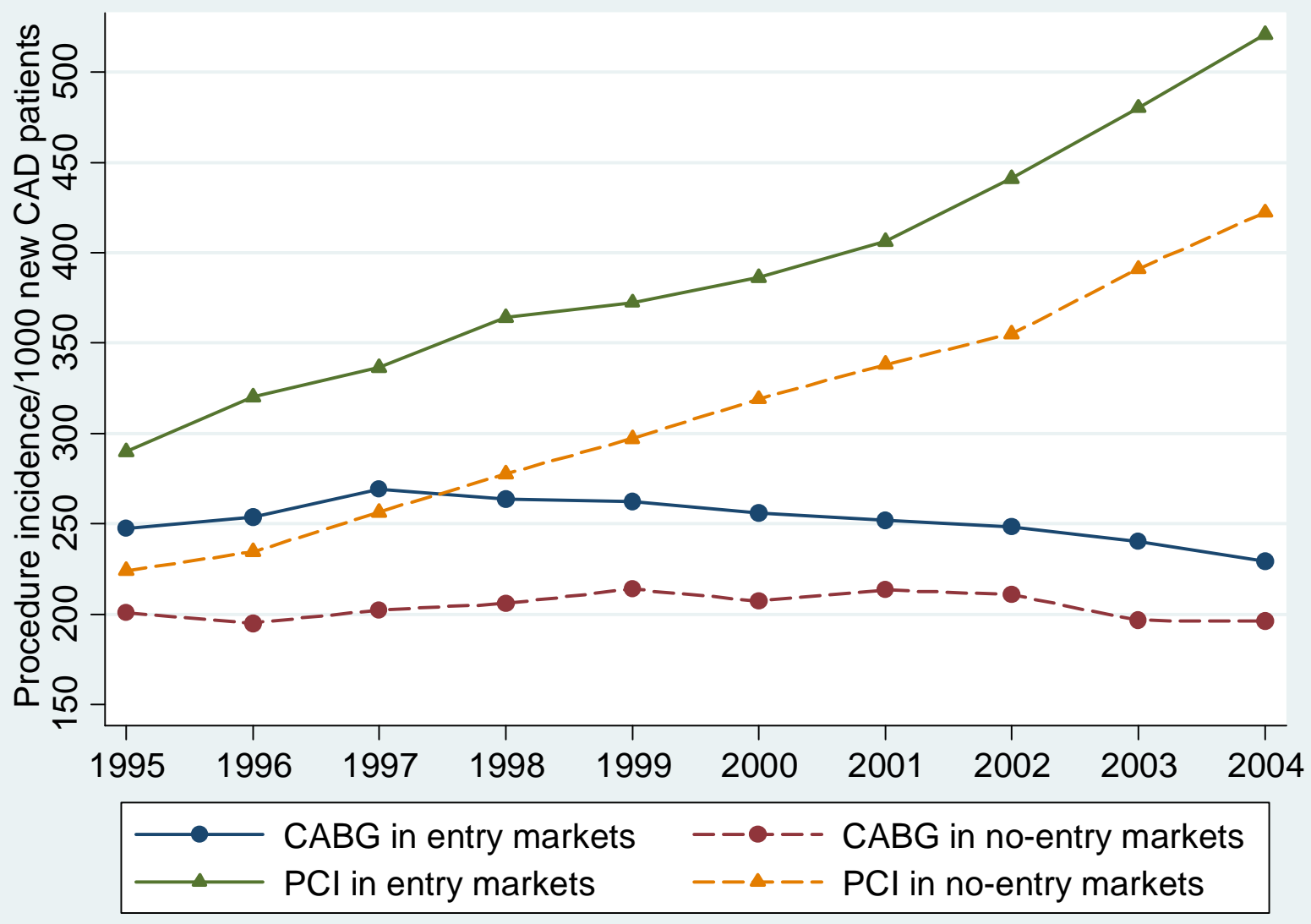


Figure 4 Regression-Adjusted Three-Month Probabilities of CABG for First-Time CAD Patients, $1995-2004$

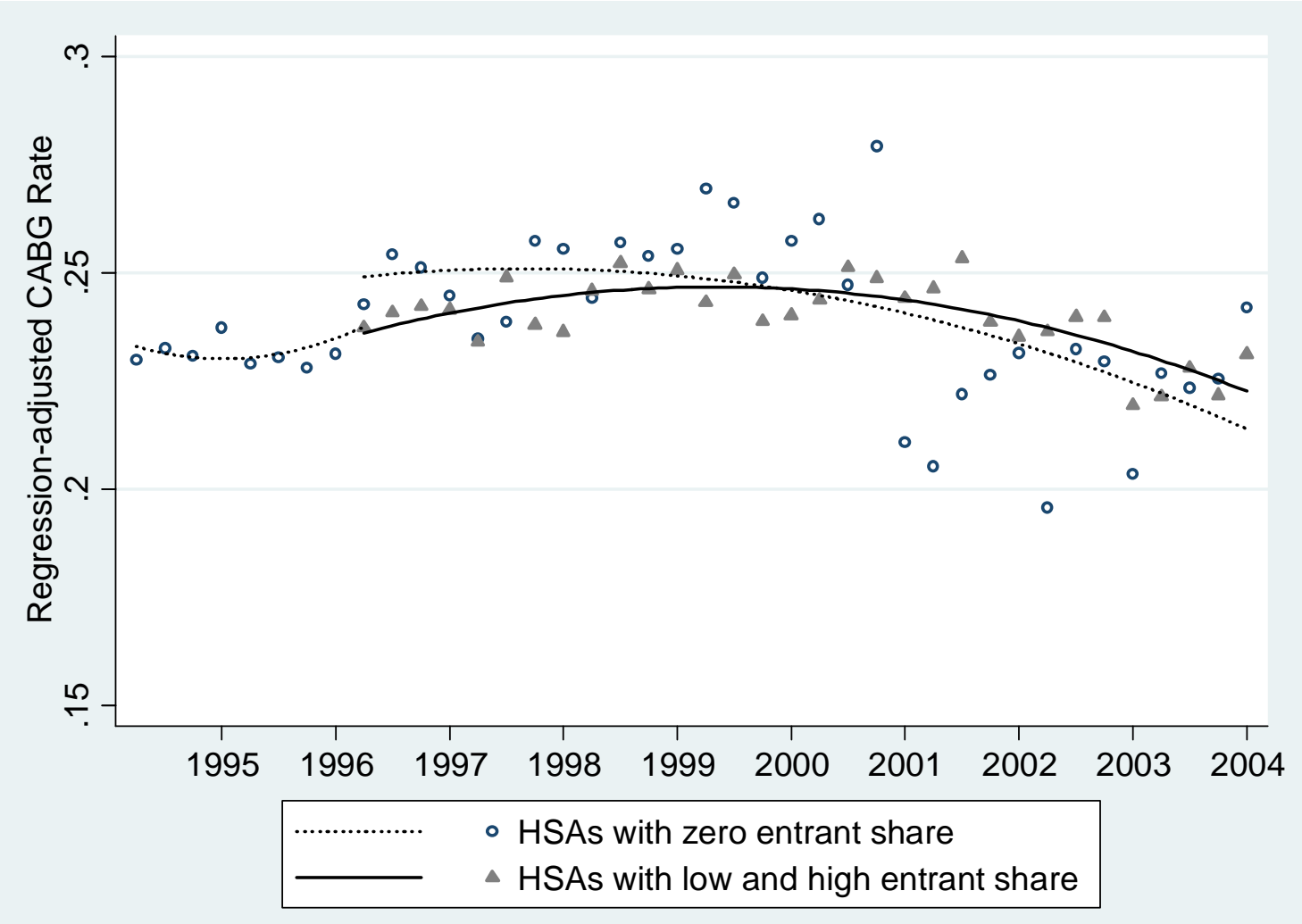

Note: Fitted trends are quadratic, allows to vary across the before- and after-CON repeal period, and are adjusted for factors included in equation (2b). 
Figure 5 Regression-Adjusted Three-Month Probabilities of PCI for First-Time CAD Patients, $1995-2004$

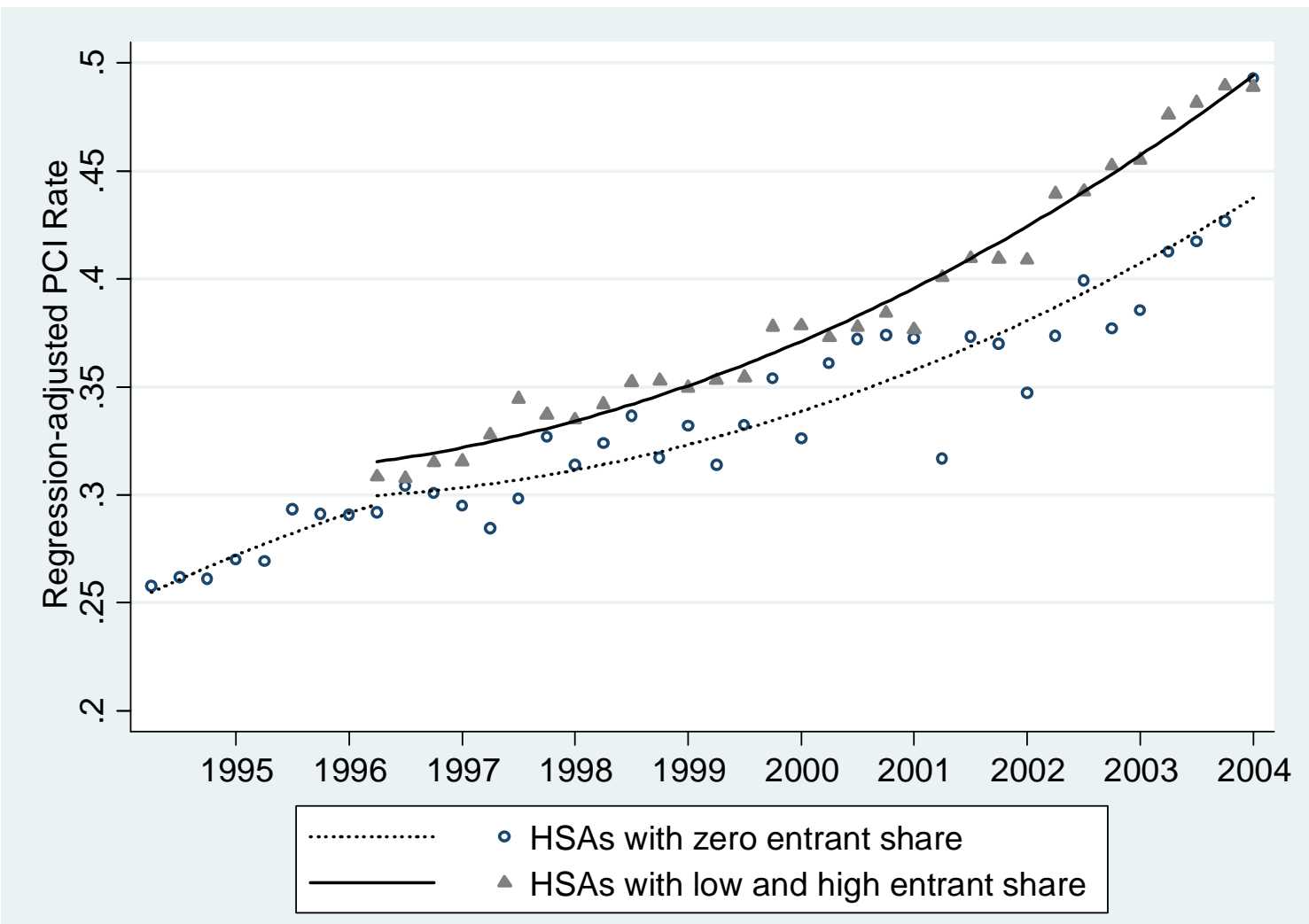

Note: Fitted trends are quadratic, allows to vary across the before- and after-CON repeal period, and are adjusted for factors included in equation $(2 b)$. 


\section{Patient Characteristics}

Full Sample of Patients newly diagnosed as CAD

Gender $(1=$ male $)$

Race Group

White

Black

Asian

Other races

Age group

Age $<=49$

Age 50-59

Age 60-69

Age 70-79

Age $80+$

Emergency room admission

Transferred admission

Urban residence

Illness Severity Upon Admission

MediQual $=0$

MediQual $=1$

MediQual $=2$

MediQual=3

MediQual $\geq 4$

Major indications at admission

Cardiogenic shock

Hypertension

Dialysis

Heart failure

Diabetes

Renal failure

AMI

Prior $\mathrm{CABG}$

Prior PCI

Medicare

Medicaid

HMO penetration rate at the county of residence
Mean

0.586

0.094

0.846

0.057

0.002

0.095

0.171

0.241

0.3

0.193

0.478

0.161

0.71

0.069

0.452

0.323

0.14

0.017

0.02

0.535

0.008

0.196

0.273

0.043

0.4

0.047

0.084

0.587

0.046

0.406
Medicare FFS Patients traveling within 50 miles for CABG or PCI

$\underline{\text { Mean }}$

$\underline{\text { Stdv }}$

$\underline{\text { Stdv }}$

0.493

0.581

0.493

0.292

0.095

0.293

0.361

0.87

0.336

0.232

0.034

0.181

0.046

0.001

0.036

0.293

0.012

0.111

0.033

0.179

0.256

0.436

0.52

0.5

0.179

0.383

0.395

0.252

0.434

0.221

0.415

0.784

0.411

0.454

0.253

0.043

0.203

0.427

0.495

0.432

0.495

0.468

0.094

0.291

0.128

0.004

0.064 


\begin{tabular}{|c|c|c|c|c|}
\hline & \multicolumn{2}{|c|}{$\begin{array}{c}\text { Full Sample of Patients newly } \\
\text { diagnosed as CAD }\end{array}$} & \multicolumn{2}{|c|}{$\begin{array}{c}\text { Medicare FFS Patients } \\
\text { traveling within } 50 \text { miles for } \\
\text { CABG or PCI }\end{array}$} \\
\hline & $\underline{\text { Mean }}$ & $\underline{\text { Stdv }}$ & $\underline{\text { Mean }}$ & $\underline{\text { Stdv }}$ \\
\hline \multicolumn{5}{|l|}{ Hospital Characteristics } \\
\hline Not-for-profit & 0.991 & 0.092 & 0.996 & 0.066 \\
\hline Bed size $<200$ & 0.196 & 0.397 & 0.063 & 0.242 \\
\hline Bed size $200-400$ & 0.326 & 0.469 & 0.296 & 0.456 \\
\hline Bed size $>400$ & 0.478 & 0.5 & 0.642 & 0.479 \\
\hline Member of any health system & 0.707 & 0.455 & 0.766 & 0.424 \\
\hline Teaching & 0.485 & 0.5 & 0.606 & 0.489 \\
\hline COTH membership & 0.345 & 0.475 & 0.427 & 0.495 \\
\hline CABG volume $\geq 200$ & 0.624 & 0.484 & 0.848 & 0.359 \\
\hline PCI volume $\geq 400$ & 0.556 & 0.497 & 0.776 & 0.417 \\
\hline \# of patients & 714088 & & 147684 & \\
\hline \# of hospitals & 195 & & 79 & \\
\hline
\end{tabular}




\section{Appendix: Predicting Entrant Market Share}

In equations $1-3, S_{k t}$ is the entrant market share at time $t$ in Hospital Service Area (HSA) $k$, based on patients' area of residence (assigning entrant share based on where patients were treated can introduce endogeneity, since patients' hospital choice may be affected by unobserved determinants of the hospitals; Similarly, the hospital's entry choice may depend on anticipated patient flows, which in turn depends on unobserved determinants of patient population). To further address the identification issues, we adopt Kessler and McClellan's (2000) method of constructing hospital market share to our special context of entry. The analysis is conducted in three steps: First, calculate an array of relative distances between the choice hospital and alternative hospitals in the patient's choice set; these provide instrumental variables. Second, estimate a patient level hospital choice model, incorporating patient characteristics, hospital traits, and relative distances. Third, obtain predicted probabilities of choosing an entrant hospital and sum up the probabilities within each area to obtain market shares. Estimates are implemented separately for CABG and PCI.

\section{Step 1:}

We specify an array of distance variables specified as follows:

$$
\begin{gathered}
V_{i j}=\sum_{h=1}^{H}\left[\gamma_{1}^{h} \cdot D_{i j}^{h+} \cdot Z_{j}^{h}+\gamma_{2}^{h} \cdot D_{i j}^{h+} \cdot\left(1-Z_{j}^{h}\right)+\gamma_{3}^{h} \cdot D_{i j}^{h-} \cdot Z_{j}^{h}+\gamma_{4}^{h} \cdot D_{i j}^{h-} \cdot\right. \\
\left.\left(1-Z_{j}^{h}\right)\right],
\end{gathered}
$$

where $Z_{j}^{h}$ is a binary indicator of trait $h$ in hospital $j$. The exogenous impact of travel cost is specified as an array of differential distances between the choice hospital and the patient's closest alternative hospital $(D)$, where the alternative is specified separately for each hospital trait. Thus, for $\mathrm{H}$ hospital traits, there are $2 \times H$ distance-trait interactions terms included in $V$. For example, if hospital $j$ is not-for-profit, then the patient's utility from choosing hospital $j$ depends on $D_{i j}^{1+}$, the additional distance she has to travel beyond her closest not-for-profit hospital (a good substitute) and $D_{i j}^{1-}$, the additional distance she has to travel beyond her closest for-profit hospital (a poor 
substitute). ${ }^{27}$

The choice set for each individual $i$ at year $t$ is comprised of all non-federal hospitals offering at least five $\mathrm{CABG}(\mathrm{PCI})$ within 50-mile radius of her residence. We compute the straight line distance between the geographic centroid of the zip code of a patient's residence and the exact location (longitude and latitude) of the hospital using the Geographic Information System.

Step 2.

In this step, we estimate a patient-level conditional logit (CL) model of hospital choice separately for CABG and PCI patients by each year in the post CON period, 1997-2004. An individual patient $i$ 's utility from going to hospital $j$ is a function of the individual's characteristics, the hospital's attributes, and they array of relative distances previously described. Using vector notation we define

$$
W_{i j}=X_{i}^{\prime} \cdot Z_{j}^{\prime} \beta
$$

$W$ is specified as a nonparametric function of the interaction between individual's characteristics $X_{i}^{\prime}$ are fully interacted with binary indicators of all hospital characteristics $Z_{j}^{\prime}{ }^{28}$

Using the previous notation the individual $i$ 's indirect expected utility from choosing hospital $j$ can be summarized as

$$
U_{i j}=W\left(X_{i} ; Z_{j}^{1}, \ldots, Z_{j}^{H}\right)+V\left(D_{i j}^{1+}, \ldots, D_{i j}^{H+}, D_{i j}^{1-}, \ldots, D_{i j}^{H-} ; Z_{j}^{1}, \ldots, Z_{j}^{H}\right)+\epsilon_{i j} .
$$

Each hospital $j$ is characterized by $H$ binary characteristics $Z_{j}^{1}, \ldots, Z_{j}^{H}$, and the utility of individual $i$ from choosing $j$ depends on the relative distances to its good substitutes (same-type)

\footnotetext{
${ }^{27}$ This specification allows for $2 \times H$ relative distances that influence $V_{i j}: D_{i j}^{h+}$ equals the distance from $i$ to hospital $j$ minus the distance from $i$ to the closest hospital $j^{\prime}$ with $Z_{j \prime}^{h}=Z_{j}^{h}$, and $D_{i j}^{h-}$ equals the distance from $i$ to hospital $j$ minus the distance from $i$ to the closest hospital $j^{\prime}$ with $Z_{j}^{h} \neq Z_{j}^{h}$.

${ }^{28}$ Vector $X_{i}$ includes age categories, gender, race categories, source of admission, illness severity, and an indicator of living in urban counties. Vector $Z_{j}$ includes indicators of not-for-profit, bed size between $200-$ 400 , bed size above 400, more than 20 full-time residents, COTH member, hospital system member, CABG cases above 200 in the prior year, and PCI cases above 400 in the prior year.
} 
and the relative distances to its poor substitutes (different-type). To allow for any nonparametric relationship between distances and patient's choice, we categorize $D_{i j}^{h+}$ and $D_{i j}^{h-}$ into four quartile dummies based on the distribution of the respective relative distance. That is, $D_{i j}^{h+}=$ $\left(D D 1_{i j}^{h+}, \ldots, D D 4_{i j}^{h+}\right)$ and $D_{i j}^{h-}=\left(D D 1_{i j}^{h-}, \ldots, D D 4_{i j}^{h-}\right)$.

Finally, let $Y_{i j}=1$ if individual $i$ is treated at hospital $j$, and $=0$ otherwise. Using McFadden's (1973) conditional logit, the probability of individual $i$ choosing hospital $j$ equal to

$$
\operatorname{Pr}\left(Y_{i j}=1\right)=\frac{\exp \left(W_{i j}+V_{i j}\right)}{\sum_{j \in J_{i}} \exp \left(W_{i j}+V_{i j}\right)} .
$$

Equation (A-4) is estimated using maximum likelihood. Given that private insurance plans ranging from HMOs to PPOs constrain their memberships choices to hospitals within their networks, we estimate equation (A-4) using the sample of Medicare fee-for-service enrollees whose hospital choices are essentially unrestricted. Following Town and Vistnes (2001) and Ho (2006) we use the parameter values from the Medicare equation to obtain predicted choices for the all-payer sample. Both studies showed that this method provides reasonable proxies for other payers. ${ }^{29}$ Descriptive statistics for the patient and hospital characteristics of the Medicare-FFS sample are reported in column (2) of Table A-1.

\section{Step 3}

Estimated coefficients then are used to predict $\hat{d}_{j k}$, the expected demand for CABG (PCI) at hospital $j$ from patients living in market $k$, for patients of all insurance types:

$$
\hat{d}_{j k}=\sum_{i \in k} \hat{\pi}_{i j}
$$

where $\hat{\pi}_{i j}$ denotes the predicted probability of individual $i$ receiving procedure CABG(PCI) at hospital $j$.

Let $S_{k}$ be the entrants' market share in HSA $k$. It can be computed as the number of

\footnotetext{
${ }^{29}$ Ho (2006) and Town and Vistnes (2001) implicitly assume that the Medicare that Medicare patients have similar preference for hospitals as their managed care counterparts conditional on diagnosis, distances, and other demographics.
} 
patients living in market $k$ who go to new centers for cardiac procedures as a proportion of the total number of patients in market $k$ :

$$
S_{k}=\frac{\sum_{i \in E n t} \hat{d}_{j k}}{\sum_{j \in J} \hat{d}_{j k}},
$$

where Ent denotes the set of entrant hospitals, and $J$ denotes the full set of hospitals providing $\mathrm{CABG}(\mathrm{PCI})$ procedure. Each patient $i$ then is assigned an entrant share $S_{k}$ at his/her market of residence (instead of at the admitting hospital). 